\author{
UNIVERSIDADE DE SÃO PAULO \\ INSTITUTO DE PSICOLOGIA
}

CARLA JORDÃO SUAREZ

\title{
Efeitos de histórias de cooperação e não- cooperação sobre a produção de iniquidade desfavorável
}




\section{Efeitos de histórias de cooperação e não- cooperação sobre a produção de iniquidade desfavorável}

Dissertação apresentada ao Instituto de Psicologia da Universidade de São Paulo, como parte dos requisitos obrigatórios para obtenção do grau de Mestre em Psicologia.

Área de concentração:

Psicologia Experimental

Orientador: Prof. Dr. Marcelo Frota Lobato Benvenuti

São Paulo

2015 
Nome: Suarez, Carla Jordão

Título: Efeito de histórias de cooperação e não-cooperação sobre a produção de iniquidade desfavorável.

Dissertação apresentada ao Instituto de Psicologia da Universidade de São Paulo para obtenção do título de Mestre em Psicologia

Aprovada em:

\section{Banca Examinadora}

Prof.:

Instituição: Assinatura:

Prof.:

Instituição: Assinatura:

Prof.:

Instituição: Assinatura: 


\section{AGRADECIMENTOS}

Primeiramente agradeço àqueles que tiveram participação direta no meu Mestrado.

Ao Marcelo, meu orientador. Obrigada por me acolher tão bem desde meu primeiro dia na universidade, por permitir que eu cresça como pesquisadora e aluna e por ter confiado em meu trabalho. Obrigada por ter me orientado nessa longa caminhada. Foi um prazer aprender com você.

Ao Caê Costa e à Josele Abreu-Rodrigues, por terem aceito fazer parte de minha banca e terem dado contribuições tão valiosas a meu trabalho.

Ao Caê Costa, novamente. Meu primeiro e querido mestre. Graças a sua paixão pela área, sua paixão por ensinar e sua solidariedade em passar conhecimento, decidi seguir na área acadêmica. Sem você, provavelmente, eu não estaria escrevendo estes agradecimentos hoje.

Aos colegas de laboratório que acompanharam minha jornada, acrescentando importantes discussões a meu trabalho: Pedro Cabral, Lorena Alves, Angelo Sampaio, Natália Marques, Thaís Toledo, Flávia Duarte, Sirlene Miranda, Natasha Hayamizu e César Augusto.

À Liane Dahás, pela enorme ajuda com a parte estatística dos meus resultados, pela disponibilidade e pelas importantes contribuições.

Ao Conselho Nacional de Desenvolvimento Científico e Tecnológico (CNPq), pela bolsa concedida, que viabilizou minha permanência em São Paulo.

A meus queridos confederados: Fernando Nascimento, Pedro Cabral, Amílcar Fonseca, Eduardo Souza, Angelo Sampaio, Natália Marques e César Augusto.

À Sônia Maria Caetano, pela gentileza e acolhimento. Para mim, você é uma grande amiga e uma pessoa iluminada que tive o imenso prazer de conhecer durante o Mestrado.

Agradeço também àqueles que estiveram a meu lado nessa caminhada.

À Cris, minha irmã, minha outra metade, que sempre esteve e está a meu lado. Eu não teria conseguido sem você. Você é minha força, incentivo e alicerce.

Cezarina, a vó mais linda do mundo. Você é meu exemplo de vida, vitória, amor e meu melhor aconchego. Obrigada por me amar incondicionalmente e por ser a vó mais perfeita que já existiu. 
À Camila, minha irmã mais velha, que sempre foi exemplo de perseverança e superação.

A meus pais, Mário e Angélica, pelo apoio, incentivo ao estudo e por sempre acreditar em mim. O que sou hoje é graças a vocês.

Ao Fernando, amigo, namorado e parceiro de vida. Não tenho palavras para agradecer por todo o cuidado, carinho e paciência. Sei que não foi fácil e sei também que não poderia ter escolhido pessoa melhor para dividir toda a alegria e a angústia que a vida traz.

Ao Pedro Cabral, melhor amigo. Presente que a universidade me deu antes mesmo de entrar para o Mestrado. Você viveu comigo todas as etapas e sempre esteve por perto. Obrigada pela sincera amizade.

A meus grudinhos eternos: Camila Belavenuta e Camila Daliane. A amizade de vocês é o melhor e mais valioso presente que a graduação me poderia ter dado. Melhores amigas que qualquer pessoa pode ter.

Ao meu casal ‘curintiano’ preferido: Taty Porto e Matheus Aoki. Vocês me receberam de braços abertos em São Paulo e me fizeram sentir como se eu fosse parte da família. Obrigada por isso e pela verdadeira amizade.

À Haiana Alves, a pernambucana mais linda e divertida que eu já conheci e amizade para toda a vida.

À Raquel Lacerda, que, além de uma amiga sem igual, é uma pesquisadora exemplar a quem admirei desde minha graduação. Você foi meu apoio na graduação e assim se mantém até hoje.

À Talita Cunha, por todos os momentos que dividimos juntas e por me fazer sentir como se eu ainda estivesse em Londrina.

À Crisavânia Viana, minha amiga-irmã. Amizade para mais de 20 anos - e isso é impossível descrever em palavras. Pensar em você é sentir alegria no mesmo instante.

À Fabi Moraes, que sempre se fez presente mesmo tão longe. Obrigada pela amizade e carinho de tantos anos.

Agradeço também a Deus pela sincronia com a qual as coisas acontecem na minha vida.

Todos vocês fizeram que tudo se tornasse possível. Obrigada a todos. 


\section{RESUMO}

Suarez, C. J. (2015). Efeitos de histórias de cooperação e não-cooperação sobre a produção de iniquidade desfavorável. Dissertação de Mestrado, Instituto de Psicologia, Universidade de São Paulo, São Paulo.

O presente trabalho investigou o efeito de histórias de cooperação e não-cooperação sobre a escolha de um participante entre uma alternativa de cooperação e uma alternativa individual. Os participantes formaram duplas com um confederado e ambos escolheram entre cartões azuis e verdes. Cooperação foi definida como o participante e o confederado escolherem o cartão azul e a alternativa individual foi definida como um ou ambos escolherem o cartão verde. Os participantes foram expostos a três fases experimentais: Fase Inicial, Fase de História e Fase de Teste. Na Fase Inicial (4 tentativas) e na Fase de História (15 tentativas), quando o participante e confederado escolhiam o cartão azul, o participante recebia 5 pontos e o confederado 2 pontos. Quando um dos dois ou ambos escolhiam o cartão verde, ambos recebiam 2 pontos. Na Fase de Teste (15 tentativas), quando o participante e confederado escolhiam o cartão azul, o confederado recebia 5 pontos e o participante 2 pontos. Caso um ou ambos escolhessem o cartão verde, os dois recebiam 2 pontos. Os participantes foram distribuídos em dois grupos (Cooperação e Individual) que se diferenciavam pela escolha do confederado. Em ambos os grupos, na Fase Inicial, o confederado escolheu o cartão verde e azul alternadamente. Na Fase de História e na Fase de Teste do Grupo Cooperação, o confederado escolheu o cartão azul em todas as tentativas. Enquanto que no Grupo Individual, o confederado escolheu o cartão verde na Fase de História e o cartão azul na Fase de Teste. Os resultados indicaram que os participantes do Grupo Cooperação escolheram o cartão azul em aproximadamente 11 de 15 tentativas na Fase de Teste, produzindo iniquidade desfavorável para ele, enquanto os do Grupo Individual escolheram o cartão azul aproximadamente em 1 de 15 tentativas. Conclui-se que a escolha de um dos participantes (ou confederado) de uma dupla entre produzir ou não iniquidade favorável para o outro participante precisa ser cuidadosamente considerada nos estudos sobre cooperação, já que pode alterar inclusive a função da iniquidade de reforços.

Palavras-chave: Cooperação. História experimental. Iniquidade de reforço. 


\begin{abstract}
Suarez, C. J. (2015). Effects of stories of cooperation and non-cooperation on the iniquity production. Master Dissertation. Instituto de Psicologia, Universidade de São Paulo, São Paulo.

This study aimed to investigate what is the effect of different stories of cooperation and non-cooperation on the choice of a participant of a cooperation alternative and a single alternative. Participants worked in pairs with a confederate, and each pair had the task of choosing between a blue card and a green card. If the participant and the confederate chose the blue card, cooperation alternative came into effect; if either or both choose the green card, the individual alternative entered into force. Participants were exposed to three experimental phases: Initial Phase, Phase History and Test Phase. In the Initial Phase (four attempts) and History Phase (fifteen attempts), when the participant and confederate chose the blue card, the participant received 5 points and the confederate 2 points. When either or both chose green cards, both received 2 points. In the Test Phase (fifteen attempts), when the participant and confederate chose the blue card, the confederate received 5 points and the participant 2 points. If either or both choose the green card, both received 2 points. Participants were divided into two groups (Cooperation and Single), that differed by the choice of confederate. In both groups, in the Initial Phase, the confederate chose the blue card and green alternately. In Phase History and Test Phase of Cooperation Group, the confederate chose the blue card in all attempts. While in the Individual Group the confederate chose the green card in the History Phase and the blue card in the Test Phase. Results indicated that the participants of the Cooperation Group chose the blue card more than 11 of the attempts in the Test Phase, producing unfavorable iniquity for it; while the Individual Group chose at least 2 of attempts. We conclude that the experimental history is an important variable to be considered in studies of cooperation, and the fact that the reinforcements of iniquity does or does not aversive properties depends more on other variables than necessarily of iniquity itself.
\end{abstract}

Keywords: Cooperation. Experimental history. Iniquity reinforcements. 


\section{LISTA DE FIGURAS}

Figura 1. Sala de coleta de dados 28

Figura 2. Disposição dos cartões na mesa do participante e do confederado. 28

Figura 3. Número total de escolhas do cartão azul e do cartão verde de cada participante do Grupo Cooperação e do Grupo Individual nas Fases Inicial, de História e de Teste 36

Figura 4. Média de escolhas do cartão azul dos participantes do Grupo Cooperação e do Grupo Individual na Fase de História e na Fase de Teste. A barra cheia representa a média de escolhas do cartão azul de todos os participantes do Grupo Cooperação e a barra vazia representa a média total de escolhas do cartão azul de todos os participantes do Grupo Individual

Figura 5. Número total de escolhas do cartão azul de cada grupo em blocos de três tentativas na Fase de História. Os participantes do Grupo Cooperação estão representados com círculos cheios e os participantes do Grupo Individual estão representados com círculos vazios. Cada bloco de três tentativas representa a soma das escolhas do cartão azul dos onze participantes de cada grupo naquele bloco 38

Figura 6. Número total de escolhas do cartão azul de todos os participantes de cada grupo em blocos de três tentativas na Fase de Teste. Os participantes do Grupo Cooperação estão representados com círculos cheios e os participantes do Grupo Individual estão representados com círculos vazios. Cada bloco de três tentativas representa a soma das escolhas do cartão azul dos onze participantes de cada grupo naquele bloco 39

Figura 7. Probabilidade relativa de escolha do cartão azul na Fase de Teste e o ganho relativo na Fase de História de cada participante do Grupo Cooperação e do Grupo Individual. O círculo cheio representa os participantes do Grupo Cooperação e o círculo vazio representa os participantes do Grupo Individual 


\section{LISTA DE TABELAS}

Tabela 1. Pontos recebidos pelo participante e pelo confederado de ambos os grupos experimentais, número de tentativas em cada fase experimental e escolha do

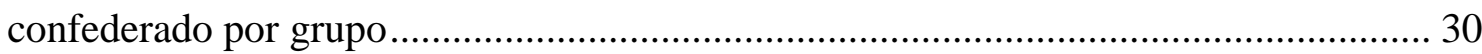


LISTA DE SIGLAS

IET Intervalo entre tentativas

P1 Participante 1

P2 Participante 2

TCLE Termo de consentimento livre e esclarecido

VT Tempo variável 


\section{SUMÁRIO}

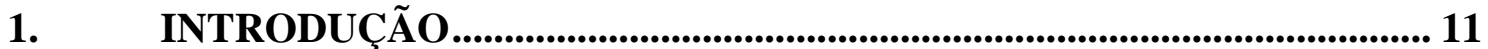

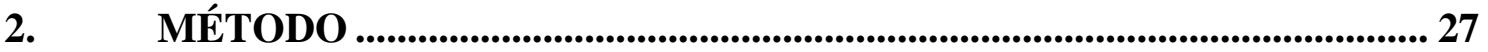

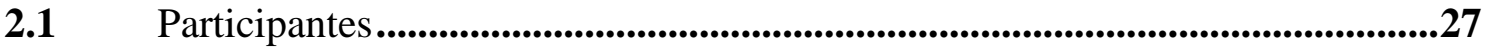

2.2 Ambiente e Material .........................................................................................................27

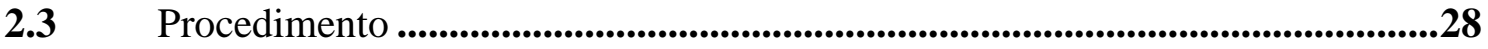

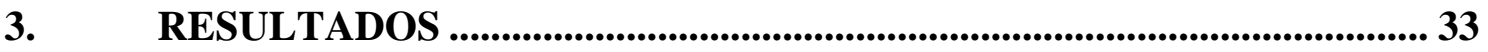

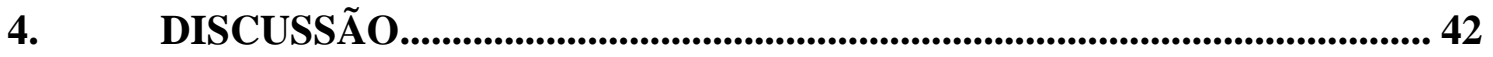

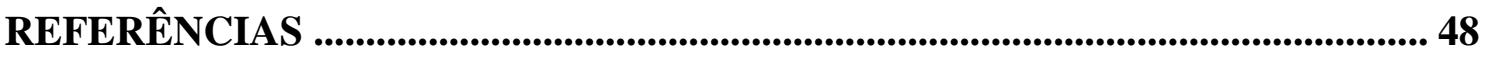

APÊNDICE A. Termo de Consentimento Livre e Esclarecido ................................... 50 
Contingências de reforço especificam relações de dependência entre situações antecedentes, respostas e consequências dessas respostas (Skinner, 1969; Todorov, 2012). A noção de contingência de reforço é um importante instrumento para a Análise do Comportamento, tanto para análise das respostas dos indivíduos em relação ao seu meio não social, como, também, para análise de interações entre dois ou mais indivíduos. Em 1953, Skinner já chamava a atenção para o fato de que o ambiente de um indivíduo (antecedente e/ou consequente) pode ser composto pela resposta de outro(s) indivíduo(s) e que quando a emissão e/ou o reforçamento da resposta de um indivíduo depende, ao menos parcialmente, da resposta de outro(s), denomina-se essa relação de comportamento social (Keller \& Schoenfeld, 1950; Skinner, 1953).

A partir da definição de comportamento social de Skinner foi possível descrever as contingências de reforço de algumas relações sociais comuns no dia-a-dia, como por exemplo, a cooperação e a competição. Cooperação e competição são relações que ocorrem em um contexto particular de contingências que especificam qual resposta deve ser emitida naquele contexto e o critério para que essa resposta seja reforçada. Nessas duas relações, os reforços são interdependentes, ou seja, os reforços obtidos por um indivíduo são, ao menos parcialmente, dependentes da resposta de outro(s) indivíduo(s) também envolvidos na contingência. Dessa forma, a resposta de um indivíduo acaba por se tornar um estímulo discriminativo para a resposta de outro indivíduo (Schmitt, 1998).

Um estudo pioneiro que mostra a interdependência do reforço em um episódio social foi realizado por Azrin e Lindsley (1956). Os autores tinham como objetivo investigar a possibilidade de desenvolver, manter e extinguir a cooperação entre duas crianças somente com a apresentação e a não-apresentação do reforço contingente ao cooperar. Dez duplas formadas por crianças entre 7 e 12 anos de idade tinham que realizar uma tarefa na qual a liberação do reforço dependia da resposta de ambos participantes das duplas. Os participantes sentavam em lados opostos de uma mesa, um de frente para o outro, e podiam se comunicar entre si. Em frente de cada participante, na mesa, havia 3 buracos (esquerdo, central e direito) e uma vareta de metal. Cada participante poderia manipular a sua vareta de metal e inseri-la em um de três buracos. A resposta de cooperação ocorria quando os participantes colocavam a vareta de metal em buracos que estivessem dispostos um em frente do outro em um intervalo de 0,04 s (por exemplo, quando um participante colocasse a vareta no buraco central, o outro participante deveria 
colocar a sua vareta também no buraco central em até 0,04 s). Quando a resposta cooperativa era emitida, uma luz vermelha no centro da mesa piscava e uma única bala de goma caia em um recipiente acessível a ambos os participantes. Caso os participantes colocassem as varetas em buracos de direções diferentes (um participante colocasse no buraco central e o outro participante colocasse no buraco esquerdo), a resposta era considerada individual e nenhum reforço era liberado. Cada dupla participou de uma única sessão composta por três condições. Na primeira condição, o reforço era apresentado após cada resposta de cooperação. Essa condição teve duração de pelo menos 15 min e as duplas passavam para a condição seguinte quando a taxa de respostas permanecesse estável por 5 min. Na segunda condição, nenhum reforço era apresentado após a emissão da resposta de cooperação (extinção) por pelo menos 15 min. A taxa de resposta deveria permanecer estável por 5 min em extinção para que as duplas retornassem para a primeira condição, com apresentação do reforço para cooperação. A segunda exposição à condição de reforço durou até que a taxa de resposta de cooperar permanecesse estável por $3 \mathrm{~min}$. Os resultados indicaram que todas as duplas emitiram a resposta de cooperação nos primeiros 10 min da primeira condição. Em extinção, a taxa de resposta de cooperação foi diminuindo gradualmente. Com o retorno à condição de reforço por cooperar, houve um aumento quase imediato na taxa de resposta.

No estudo de Azrin e Lindsley (1956) há alguns aspectos interessantes que permitiram avanços na análise experimental do comportamento social. Em primeiro lugar, o que foi considerado uma "resposta" não foi a ação de um organismo singular, mas a coordenação de respostas das duas crianças da dupla. Essa coordenação foi definida como “resposta de cooperação”. Para que a resposta de cooperação fosse emitida, a resposta de um dos participantes deveria ficar sob controle discriminativo da resposta do outro participante. Ou seja, a resposta de cooperação só acontecia quando os dois participantes coordenassem suas respostas. Logo, a liberação do reforço era dependente da resposta de ambos os participantes. Essas duas características (a resposta de um se tornar um estímulo discriminativo para a resposta do outro e a interdependência do reforço) estão presentes tanto nas relações de cooperação como nas relações de competição.

Cooperação e competição compartilham da mesma característica quanto à interdependência do reforço, porém, diferem na forma como o reforço é distribuído entre os indivíduos envolvidos. Na competição, quando a resposta de um dos indivíduos de uma dupla ou um grupo é reforçada, este fato anula ou diminuiu os reforços disponíveis para os 
outros indivíduos envolvidos. Na cooperação, a resposta de todos os indivíduos (dois ou mais) é reforçada quando esses indivíduos coordenam suas respostas e cumprem um requisito específico estabelecido pela contingência.

A cooperação pode ser estudada com a programação de um esquema simples, como no estudo de Azrin e Lindley (1956), em que a escolha do participante pode ser avaliada em termos de ocorrência ou não da cooperação. Nesse caso, não cooperar envolve necessariamente deixar de receber reforço. Uma alternativa metodológica envolve a programação de esquemas concorrentes, em que os participantes devem escolher entre cooperar, competir ou outra contingência alternativa (e.g. divisão de tarefas, trabalho individual). Nesse caso, consequências diferentes podem ser planejadas para cada uma das alternativas (e.g. Mithaug, 1969; Schmitt \& Marwell, 1971a, 1971b). A contingência individual é uma das possibilidades utilizadas como contingência alternativa e, diferente da cooperação e da competição, a resposta do indivíduo e o reforço obtido são independentes da resposta e do reforço do(s) outro(s) indivíduo(s) que também estão envolvidos na tarefa (Schmitt, 1998). Dentre as variáveis que determinam a escolha de um participante por cooperar versus trabalhar individualmente ou competir versus trabalhar individualmente pode-se citar: a magnitude do reforço (e.g. Mithaug, 1969), a história de exposição a esquemas de reforço (e.g. Buskit \& Morgan, 1987), a possibilidade de perder pontos para o parceiro (e.g. Schmitt \& Marwell, 1971a), o custo da resposta (e.g. Dougherty \& Cherek, 1994), o uso de instruções referentes às contingências em vigor (e.g. Abreu-Rodrigues, Natalino \& Aló, 2002) e a iniquidade de reforços.

Um aspecto extra que deve ser analisado em situações de cooperação e competição é a distribuição de ganhos (reforços) entre os participantes que os recebem de modo interdependente. Os ganhos podem ser distribuídos igualmente ou não entre os indivíduos (Schmitt, 1998). Nesse caso, a distribuição resultante pode ser equitativa ou não. A iniquidade de reforços (distribuição não equitativa) é definida como a diferença entre reforços obtidos pelos membros de uma dupla ou de um grupo após completarem uma tarefa específica. A iniquidade pode ser manipulada nos estudos experimentais por meio da magnitude, da probabilidade ou da forma de distribuição dos reforços, como por exemplo, atraso do reforço (de-Farias, 2001). Pesquisadores da área (e.g., Matthews, 1977; Schmitt, 1998; Schmitt \& Marwell, 1972; Shimoff \& Matthews, 1975) mostram algumas evidências que sugerem que a iniquidade de reforçadores pode ser vista como aversiva para aqueles indivíduos que estão expostos a iniquidade desfavorável. Em uma tarefa, 
quando o participante $A$ recebe mais reforços que o participante $B$, ocorre iniquidade favorável ao participante A e iniquidade desfavorável ao participante B. Com isso, em uma situação de escolha entre cooperar, competir ou trabalhar individualmente, iniquidade de reforçadores por competir ou cooperar pode contribuir para aumentar as chances de escolhas por trabalho individual (Matthews, 1979; Schmitt \& Marwell, 1972; Shimoff \& Matthews, 1975).

Um estudo que concluiu que a iniquidade de reforços pode ser aversiva (e por isso, pode controlar a escolha dos participantes entre uma alternativa de cooperação e uma alternativa individual) foi o estudo de Schmitt e Marwell (1972). Nesse estudo foram realizados três experimentos, cujo objetivo foi avaliar o efeito que diferentes magnitudes de reforço têm sobre a escolha de uma dupla de participantes entre uma alternativa de cooperação e uma alternativa individual. O setting experimental foi o mesmo nos três experimentos e será descrito a seguir. Os participantes das duplas ficaram dispostos em salas separadas, cada qual com seu equipamento de coleta. A tarefa experimental consistiu em puxar um botão do equipamento de coleta para receber pontos que seriam trocados por dinheiro no final das sessões experimentais. No equipamento de coleta havia dois contadores que exibiam os pontos acumulados por cada participante durante a sessão experimental. Cada ponto era trocado por U\$0,01. Os participantes tinham possibilidade de escolher entre duas alternativas: a alternativa individual e a alternativa de cooperação. Na alternativa individual, os participantes ganhavam pontos após puxarem o botão de resposta uma única vez. Após a liberação de cada reforço, havia um intervalo entre tentativas (IET) de 5 s. Nesse intervalo, as luzes dos equipamentos ficavam desligadas e o botão de resposta permanecia inoperante por esse período. Na alternativa de cooperação, os participantes deveriam coordenar suas respostas para receberem o reforço. Para isso, qualquer um dos participantes deveria puxar o botão do seu equipamento, acendendo uma luz por 3 s. Em seguida, o segundo participante deveria puxar o botão do seu equipamento em até $0,5 \mathrm{~s}$ após a luz ter se apagado. Após receberem o reforço, ocorria um IET de $2 \mathrm{~s}$. A alternativa de cooperação só entrava em vigor quando ambos participantes a escolhessem. Caso um dos participantes ou os dois escolhessem a alternativa individual, essa permanecia em vigor até a próxima tentativa.

As duplas dos três experimentos foram expostas a duas condições experimentais: condição de equidade (distribuição igual de pontos para ambos participantes) e condição de iniquidade (distribuição desigual de pontos na alternativa de cooperação). Durante a 
condição de equidade, independente da alternativa escolhida, os participantes recebiam a mesma quantidade de reforços. Por outro lado, quando a condição de iniquidade estivesse em vigor, ao escolherem a alternativa de cooperação, os participantes tinham a possibilidade de receber mais pontos (se comparada a alternativa individual), porém em quantidade desigual. Caso escolhessem a alternativa individual sob essa condição, os participantes recebiam a mesma quantidade de pontos. A iniquidade foi introduzida aos poucos, aumentando-se a magnitude do reforço para um dos participantes, escolhido arbitrariamente, quando ambos escolhessem a alternativa de cooperação. Os três experimentos se diferenciaram pela magnitude de reforços disponibilizadas nas alternativas. No Experimento 1 (iniquidade baixa), cada participante recebia 3 pontos após completar a tarefa de cooperação e 2 pontos ao completar a tarefa individual na condição de equidade. Durante a condição de iniquidade, ao completar a tarefa individual, cada participante recebia 2 pontos. Caso escolhessem a alternativa de cooperação, um participante recebia 3 pontos (iniquidade desfavorável) e o outro recebia 6 pontos (iniquidade favorável) após completarem a tarefa. No Experimento 2 (iniquidade moderada), a condição de equidade era idêntica ao Experimento 1. Na condição de iniquidade, cada participante recebia 2 pontos se pelo o menos um dos participantes escolhessem a alternativa individual. Caso a alternativa de cooperação fosse escolhida por ambos, um participante recebia 9 pontos (iniquidade favorável) e o outro recebia 3 pontos (iniquidade desfavorável). Por último, no Experimento 3 (iniquidade alta), cada participante ganhava 4 pontos quando escolhiam a alternativa de cooperação e 3 pontos quando escolhiam a alternativa individual durante a condição de equidade. Na condição de iniquidade, cada um recebia 3 pontos na alternativa individual. Caso escolhessem a alternativa de cooperação, um participante recebia 20 pontos (iniquidade favorável) e o outro 4 pontos (iniquidade desfavorável). Nenhuma instrução foi dada aos participantes antes da introdução das condições de iniquidade de reforço. A variável dependente do estudo foi a quantidade de tempo gasto cooperando em cada uma das condições experimentais descritas acima.

Schmitt e Marwell (1972) afirmaram que durante a condição de equidade, nos três experimentos, a proporção de tempo gasto com a alternativa de cooperação foi alta: para as 50 duplas que participaram do estudo, o equivalente de $98 \%$ do tempo foi gasto na alternativa de cooperação e $2 \%$ na alternativa individual. Na condição de iniquidade, à medida que a iniquidade foi aumentando, as duplas foram gastando menos tempo na 
alternativa de cooperação. Para os autores, os resultados corroboram claramente com a suposição de que a iniquidade é, pelo o menos, um custo importante ou uma condição aversiva para alguns participantes, e que estes evitaram a contingência que produzia maior ganho individual, escolhendo a que fornecia menor quantidade de dinheiro, mas igual.

Apesar das conclusões dos autores, nota-se variabilidade no padrão de escolhas de cada dupla dos três experimentos, de modo que não é possível uma conclusão inequívoca sobre o efeito da iniquidade no estudo. Das dez duplas que participaram do Experimento 3, somente quatro não escolheram a alternativa de cooperação durante a condição de iniquidade (três duplas não cooperaram na última sessão e uma dupla não cooperou na segunda sessão) e duas duplas diminuíram o tempo gasto com a alternativa de cooperação. Os autores não relatam a proporção de tempo gasto dessas seis duplas nas outras sessões e também não relatam os dados das outras quatro duplas que também participaram desse experimento. Com esses resultados, não é possível concluir claramente que a iniquidade de reforços possui características aversivas para os participantes expostos à tarefa. Mesmo que fosse possível afirmar que a iniquidade possui propriedades aversivas para a dupla, não seria possível afirmar para qual participante (com iniquidade favorável ou desfavorável) a iniquidade foi aversiva. Uma das dificuldades para análise do papel da iniquidade para o participante com iniquidade favorável ou desfavorável é a forma como a variável dependente foi analisada. A variável dependente foi apresentada por meio das escolhas das duplas e não da escolha de cada participante da dupla. Logo, se um dos participantes escolhesse a contingência individual, independentemente de estar exposto ou não a iniquidade desfavorável, o outro participante da dupla não teria chance de trabalhar na alternativa de cooperação. Devido a este fato, não é possível observar se a escolha ou o ganho de um dos participantes interfere na escolha do outro participante, o que seria necessário para uma análise da história de ganhos (reforço) por escolher cooperar ou trabalhar individualmente. Além disso, os dados foram apresentados por meio de uma média geral de todas as duplas dos três experimentos. Não é possível observar, em nenhuma das sessões realizadas, a proporção de tempo gasto na alternativa de cooperação e na alternativa individual de cada dupla antes e após a exposição à condição de iniquidade. Isso torna difícil a conclusão inequívoca de que a iniquidade apresentou propriedades aversivas para os participantes que a produziam.

Dois importantes resultados podem ser observados no Experimento 2 do estudo de Schmitt e Marwell (1972) em relação a aversividade da iniquidade de reforços. Após 
algumas semanas da primeira parte da coleta experimental descrita acima, as mesmas duplas foram expostas a mais duas sessões experimentais com a possibilidade de um participante receber ou retirar pontos do parceiro. A primeira sessão foi composta por 15 min da condição de equidade seguida de 90 min da condição de iniquidade e a segunda sessão foi composta por 90 min de iniquidade seguida de 15 min de equidade. Dez duplas tiveram a possibilidade de transferir pontos para o seu parceiro, enquanto as outras dez poderiam tirar pontos do seu parceiro, caso pressionassem um botão. Ambos participantes das duplas tinham acesso aos botões de resposta e poderiam pressioná-los durante a condição de iniquidade. Observou-se que as duplas que escolheram a alternativa de cooperação na primeira parte do experimento, passaram a escolher a alternativa individual caso o participante com iniquidade favorável não dividisse os pontos extras com o participante com iniquidade desfavorável; as duplas que escolheram a alternativa individual na primeira parte do experimento só passaram a escolher a alternativa de cooperação caso o participante com iniquidade favorável dividisse os pontos extras com o participante com iniquidade desfavorável ou caso o participante com iniquidade favorável permitisse que o outro participante transferisse pontos para seu próprio contador. Esses dados sugerem que quando um participante tem sob seu controle a diminuição da iniquidade e não o faz, a iniquidade desfavorável torna-se mais aversiva. Nesse caso, a resposta de um dos participantes da dupla de dividir ou não os pontos extras com o outro participante parece influenciar diretamente a resposta do outro participante.

Com o intuito de resolver alguns dos problemas do estudo de Schmitt e Marwell (1972), Shimoff e Matthews (1975, Experimento 1) propuseram um experimento no qual a resposta do participante foi analisada separadamente e a variável dependente principal do estudo foi o ponto de mudança da alternativa cooperação. O ponto de mudança foi calculado pela quantidade de pontos liberada na alternativa de cooperação para que o participante passasse a escolher essa alternativa ao invés da alternativa individual. Para maximizar os pontos, os participantes deveriam passar a escolher exclusivamente a alternativa de cooperação na primeira tentativa em que a magnitude de reforço liberada fosse maior nessa alternativa do que na alternativa individual. No geral, os participantes alteravam suas escolhas apenas uma vez a cada bloco de 20 tentativas. Cinco participantes formaram duplas com um confederado (experimentador auxiliar). As duplas foram expostas a uma situação de escolha entre uma alternativa individual e uma alternativa de cooperação, na qual a iniquidade foi manipulada através das diferentes magnitudes de 
reforço disponível em cada uma das alternativas. O participante e o confederado eram colocados em cubículos separados, cada qual com uma mesa, uma cadeira e dois consoles nos quais eram dispostos os manipulandos do estudo. O participante deveria escolher entre duas possibilidades para ganhar pontos. Ele poderia escolher a alternativa individual e pressionar os dois botões de resposta alternadamente por oito vezes ou escolher a alternativa de cooperação. Caso o confederado também tivesse escolhido esta alternativa, as contingências de cooperação entravam em vigor e o participante e confederado deveriam pressionar o botão de resposta de cooperação alternadamente por oito vezes (quatro respostas cada um). A quantidade de pontos liberada quando o participante e o confederado completavam a sequência de oito respostas de modo cooperativo ou individual eram diferentes e sofriam alterações de acordo com a condição experimental em vigor. O experimento foi composto por duas condições experimentais: equidade de reforços e iniquidade de reforços. Durante a condição de equidade de reforços, na alternativa individual, os pontos liberados eram fixos e iguais para o participante e para o confederado (a quantidade de pontos liberada variou de participante para participante). Na alternativa de cooperação, os pontos liberados também eram iguais para os dois, porém aumentavam gradativamente de 1 até 20 pontos a cada tentativa. Nessa condição, o confederado deveria copiar a escolha do participante, fazendo a sua escolha 1 a 2 s após o participante. Na condição de iniquidade de reforços, a distribuição de pontos era idêntica à condição anterior quando ambos escolhiam a alternativa individual. Porém, quando participante e confederado escolhiam a alternativa de cooperação, o confederado ganhava pontos a mais (a quantidade de pontos que o confederado ganhava a mais variou de participante para participante), além dos pontos distribuídos para ambos. Nessa condição, a escolha do confederado sempre era a alternativa em que ele ganharia mais pontos, ou seja, a alternativa de cooperação. Após cada tentativa nas duas condições descritas, os botões de resposta do equipamento permaneciam inoperantes por 9,5 s para que os pontos fossem liberados no contador de cada um deles.

Os resultados do estudo indicaram que durante a condição de equidade, os participantes maximizavam seus pontos mudando sua escolha para a alternativa de cooperação assim que a magnitude dos pontos desta alternativa ficava maior que o da alternativa individual. Na condição de iniquidade, houve muita variabilidade nos resultados de cada participante, porém, de um modo geral, os participantes escolheram a alternativa de cooperação independente do confederado receber mais pontos do que ele. Esse 
resultado, diferente de outros resultados da área (e.g. Matthews, 1977; Schmitt, 1998; Schmitt \& Marwell, 1972; Shimoff \& Matthews, 1975), indicou que, ou a iniquidade de reforços não teve propriedades aversivas para os participantes ou custo da resposta para reduzir a iniquidade de reforços era alto.

Para distinguir entre essas duas possibilidades, os autores expuseram os participantes a um botão de mudança de condição. O botão, quando disponível, permitia ao participante alterar a condição experimental que estivesse em vigor uma vez a cada bloco de 20 tentativas, sem reduzir seu próprio ganho. Caso o participante estivesse exposto a condição de iniquidade e pressionasse o botão, a condição de equidade entraria em vigor e vice-versa. O confederado não tinha a possibilidade de alterar a condição que estivesse em vigor e os participantes receberam instruções sobre a utilização e a disponibilidade do botão. Os resultados, após a exposição ao botão de mudança de condição, indicaram que a iniquidade de reforços não apresentou propriedades aversivas para os participantes, pois mesmo com a possibilidade de alterar a condição de iniquidade para condição de equidade, somente um participante dos cinco que foram expostos utilizou o botão diversas vezes.

Devido ao resultado após a exposição ao botão de mudança de condição, outra manipulação experimental foi introduzida durante a condição de iniquidade: possibilidade de o confederado dividir pontos extras com o participante. Para isso, um plug, quando disponível, permitia ao confederado dividir com o participante os pontos extras que ele recebia na alternativa de cooperação quando a condição de iniquidade estava em vigor. Nesse caso, o confederado foi instruído a dividir os pontos com o participante somente na primeira tentativa de cada bloco de 20 tentativas. Os autores expuseram três de cinco participantes a essas duas manipulações citadas acima ao mesmo tempo com o intuito de verificar se, com isso, ficaria demonstrada a propriedades aversiva da iniquidade para os participantes.

Shimoff e Matthews (1975) afirmaram que, no geral, os resultados indicaram que aumentar a magnitude de reforço para o membro da dupla que está exposto a iniquidade favorável pode alterar a escolha do outro membro da dupla exposto a iniquidade desfavorável e não tem seus ganhos modificados durante o experimento. Ou seja, os autores mostraram que a iniquidade de reforços controlou a escolha dos participantes entre as duas possíveis alternativas. Porém, a partir de uma análise mais atenta dos resultados, é possível observar que há também grande variabilidade no padrão de escolha de cada participante, assim como no estudo de Schmitt e Marwell (1972) e que novamente não é 
possível concluir com clareza o efeito da iniquidade de reforços sobre a escolha dos participantes entre cooperar ou trabalhar individualmente. No total, cinco participantes foram expostos às condições descritas acima, porém, cada um deles foi exposto a diferentes magnitudes de reforços e a diferentes manipulações experimentais, dificultando a possibilidade de se concluir qual foi o papel da iniquidade entre reforços ou das manipulações realizadas durante o experimento na escolha de cada participante. Por exemplo, o confederado ganhou 1, 5 ou 30 pontos a mais que o Participante 1, a depender da fase experimental, e foi exposto ao botão de mudança de condição. Durante a condição de equidade, o participante escolheu a alternativa individual até quando essa alternativa disponibilizasse mais pontos para ele, alternando para a alternativa de cooperação assim que os pontos desta alternativa fossem mais vantajosos. Na condição de iniquidade, o participante escolheu a alternativa individual mesmo quando a alternativa de cooperação era mais vantajosa para ele. Isso pode indicar que a iniquidade possuía propriedades aversivas para esse participante. Quando o Participante 1 foi exposto ao botão de mudança de condição, ele pressionou o botão todas as vezes assim que a condição de iniquidade entrasse em vigor, mudando a condição e não permitindo que o confederado recebesse pontos a mais. Em resumo, para esse participante pode-se afirmar que os dados corroboram outros estudos da área que afirmam que a iniquidade possui propriedades aversivas. Porém, para os outros quatro participantes, os resultados foram diferentes. O Participante 2 escolheu a alternativa de cooperação independente da magnitude da iniquidade (esse participante foi exposto a uma iniquidade desfavorável de 5, 10, 20, 50 e 90 pontos) e não pressionou o botão de mudança de condição quando disponível. Este participante foi exposto à condição na qual o confederado tinha a possibilidade de dividir os pontos extras e não dividia. No geral, a iniquidade entre reforços pareceu não ter propriedades aversivas mesmo quando o confederado recebia 90 pontos a mais que ele. Porém, após diversas exposições à condição de possibilidade de divisão de pontos do confederado, a escolha pela alternativa de cooperação diminuiu e o participante passou a pressionar o botão de mudança de condição em maior frequência para evitar a iniquidade. O mesmo aconteceu com o Participante 3 e 4 . Antes de ser exposto à condição de distribuição de pontos, o Participante 4 utilizou o botão de mudança de condição para produzir a iniquidade desfavorável e não para evita-la, como o esperado. Para finalizar, para o Participante 5, quanto maior a iniquidade de reforços, maior a preferência pela alternativa de cooperação. 
Ao analisar os estudos de Schmitt e Marwell (1972) e Schimoff \& Matthews (1975), é possível identificar que ambos manipularam mais de uma variável ao mesmo tempo (por exemplo, iniquidade de reforço, diversas exposições a diferentes condições experimentais e a possibilidade de dividir dinheiro com o parceiro) e acabaram por produzir variabilidade nos resultados (diferentes padrões de escolha entre as duas alternativas). Logo, em ambos os estudos não é possível concluir com clareza qual variável afetou diretamente a escolha do participante ou da dupla exposta às condições experimentais e definir inequivocamente qual o efeito da iniquidade favorável ou desfavorável sobre a escolha dos participantes entre cooperar ou trabalhar individualmente.

Uma questão importante a ser levantada e que parece ser fundamental nos estudos de cooperação e competição, porém ainda pouco investigada explicitamente, é a construção de história experimental com os participantes do estudo. Como é possível notar, a maioria dos estudos de cooperação e competição utiliza delineamentos muito longos e acabam por expor o participante a diversas condições e fases experimentais. Devido a isso, acaba havendo, ainda que inadvertidamente, uma história experimental de reforçamento diferencial na presença do "parceiro” com o qual o participante trabalha: há mais ou menos ganhos na presença de outra pessoa antes das condições críticas de avaliação do efeito da iniquidade favorável ou desfavorável e isso pode explicar muito da variabilidade encontrada nos estudos descritos acima. Um exemplo claro da importância de se atentar para esse aspecto é o resultado de um dos grupos (sem instrução) de um estudo realizado por Abreu-Rodrigues et al (2002). Baseado no estudo de Matthews (1979), as autoras expuseram 15 duplas de participantes, em um procedimento de escolha entre uma alternativa de competição e uma alternativa de trabalho individual. Os participantes sentavam-se em frente a uma mesa com cadeiras de frente uma para outra onde havia uma divisória que impedia o contato visual. A tarefa experimental envolvia, a cada tentativa, escolher entre dois cartões de cores diferentes, azul ou branco, ou não escolher nenhum dos cartões. Os participantes optavam pela alternativa de competição quando ambos escolhiam um dos cartões e pela alternativa individual quando um ou os dois participantes não escolhiam nenhum dos cartões e colocavam a mão sobre a mesa. Na alternativa individual, a magnitude de reforços era a mesma para ambos (sendo alterada no decorrer do experimento). Na alternativa de competição, a magnitude de reforço foi diferente para cada participante da dupla e manipulada ao longo das fases e condições experimentais. Na primeira fase do experimento, caso um ou os dois participantes da dupla escolhessem a 
alternativa individual, ambos recebiam 1 ponto. Caso ambos escolhessem a alternativa de competição, os pontos eram distribuídos da seguinte forma: o Participante 1 (P1) ganhava 5 pontos e o Participante 2 (P2) ganhava 2 pontos se os cartões fossem da mesma cor. Se os cartões escolhidos fossem de cores diferentes, o P1 ganhava 2 pontos e o P2 ganhava 5 pontos. As duplas só passavam para a fase seguinte caso escolhessem a alternativa de competição mais que $66 \%$ das tentativas. Na segunda fase, quando a alternativa de competição entrava em vigor, a distribuição de pontos era idêntica à primeira fase, porém, caso os participantes optassem pela alternativa individual, cada um dos participantes recebia 8 pontos no contador. O critério de encerramento dessa fase era o oposto da anterior, ou seja, os participantes deveriam escolher a alternativa de competição menos que 33\% das tentativas. Na fase seguinte, o objetivo foi identificar o ponto de mudança, uma distribuição de pontos que gerasse uma distribuição de escolhas aproximadamente equitativa entre as duas alternativas, e para isso, os pontos liberados na alternativa individual foi manipulado.

Finalmente, antes da última fase, as duplas foram distribuídas em três grupos: grupo Sem Instrução, os participantes não receberam nenhuma informação sobre a distribuição de pontos e sobre a reversão de pontos; grupo Instrução Precisa, os participantes receberam instruções exatas sobre como seria distribuição de pontos em cada alternativa, antes e após a reversão de pontos; e, grupo Instruções Imprecisas, os participantes receberam informações sobre a reversão de pontos, sem saber quando e quantas vezes esta reversão ocorreria. Nesta fase, ao escolherem a alternativa individual, os participantes recebiam o valor determinado na fase anterior denominado de ponto de mudança. Ao escolherem a alternativa de competição, os pontos eram distribuídos a depender da condição experimental em vigor. No total, as duplas foram expostas a cinco condições experimentais, sendo que, antes da reversão de pontos, o P2 foi exposto à iniquidade favorável e o P1 à iniquidade desfavorável (P2 ganhava mais pontos que o P1). Depois da reversão, P1 passou a ser exposto à iniquidade favorável e o P2 à iniquidade desfavorável. A ordem das condições antes da reversão foi: equidade; baixa iniquidade (P2 recebeu duas vezes mais que o P1); equidade; alta iniquidade (P2 recebeu quatro vezes mais que o P1); equidade; alta iniquidade; equidade; e baixa iniquidade. Após a reversão de pontos, as duplas foram expostas às mesmas condições, na mesma ordem, mas com a iniquidade favorecendo o P1. Para análise dos resultados, foi calculado a preferência pelas duas alternativas, sendo que valores acima de 50\% indicavam preferência por competição, 
valores abaixo de 50\% indicavam preferência por alternativa individual e valores iguais a 50\% indicavam ausência de preferência.

Os resultados indicaram que as manipulações no grau de precisão de instrução afetaram diferencialmente o controle exercido pela iniquidade de reforços sobre a escolha entre as duas alternativas. Para o grupo de Instrução Precisa, a escolha pela alternativa de competição ou pela alternativa individual foi controlada pela iniquidade de reforços. Para o grupo de Instrução Imprecisa, o percentual de escolha por competição foi similar entre os participantes das duplas em todas as condições (igual ou maior a 73\%). Porém, cabe ressaltar os resultados do grupo Sem Instrução: antes da reversão, a resposta dos participantes foi controlada pela iniquidade de reforços, ou seja, os participantes que iniciaram o experimento com iniquidade desfavorável (P1), apresentaram uma diminuição na escolha da alternativa de competição à medida que a iniquidade desfavorável aumentava, e aqueles que iniciaram a fase com iniquidade favorável (P2) ao escolher a alternativa de competição, escolheram quase que exclusivamente esta alternativa (mantevese igual a 90\%) durante todas as condições favoráveis. Após a reversão de pontos, os participantes que iniciaram com a iniquidade favorável (P2), mas que após a reversão estavam expostos a iniquidade desfavorável, apresentaram valores percentuais da escolha da alternativa de competição altos (83 a 89\%) mesmo na condição 4:1. Esse resultado indicou manutenção na escolha por competição mesmo quando eles deveriam ter diminuído esta escolha caso estivessem sob controle somente da iniquidade de pontos. Por outro lado, os participantes que iniciaram a fase com iniquidade desfavorável, mas que após a reversão estavam expostos a uma iniquidade favorável (P1), aumentaram o percentual da escolha por competição. Porém, os percentuais altos (por exemplo, 72\% na condição 4:1) foram sempre menores que aqueles apresentados pelos participantes que iniciaram o experimento ganhando mais pontos (P2).

Estes últimos resultados do grupo Sem Instrução indicam que a iniquidade de reforços não parece ter sido a única variável experimental a controlar o comportamento dos participantes. Como as autoras afirmaram, para este grupo, foi possível observar efeito de história experimental de reforçamento e punição da resposta dos participantes após a reversão. Ou seja, respostas reforçadas anteriormente persistiram mesmo após a mudança nas contingências, enquanto que respostas punidas antes da reversão foram modificados após a mudança nas contingências, porém, não tão prontamente como esperado devido a iniquidade de reforços. 
Todos os estudos analisados (Abreu-Rodrigues, et. al., 2002; Schmitt \& Marwell, 1972; Shimoff \& Matthews, 1975) manipularam diretamente as consequências liberadas em cada alternativa de escolha. Quando o participante escolhia por cooperar ou competir, entrava em vigor uma situação que preenche parte da definição de comportamento social apresentada acima, a interdependência do reforço. Com ganhos maiores ou menores resultantes, é necessário retomar a segunda parte da definição de comportamento social: o fato da resposta de um indivíduo exercer controle discriminativo sobre a resposta de outro. A manipulação direta na interdependência do reforço envolve uma variável indireta que pode afetar a resposta dos participantes: sempre que há uma história de reforço diferencial, exercido pelos ganhos diferenciais resultantes de competir, cooperar ou trabalhar sozinho, há a possibilidade de construção de controle de estímulos que pode interagir com o controle direto exercido pelas consequências. No caso dos estudos de cooperação e competição, a construção da história experimental acontece sempre na presença de um estímulo específico: outro participante/confederado. Logo, nas investigações com dois ou mais indivíduos, esse controle discriminativo pode ser exercido pela resposta de um dos participantes sobre a resposta do outro.

Um estudo que corrobora com a ideia de que a resposta de um participante/confederado pode gerar controle discriminativo para a resposta do outro em uma situação de possibilidade de cooperação é o estudo de Ribes-Iñesta, et al (2010). Os autores realizaram um estudo a fim de investigar o controle que a escolha de um confederado poderia exercer sobre a escolha de um participante. Oito estudantes universitários foram distribuídos em dois grupos com quatro duplas, sendo que cada dupla era composta por um confederado. As duplas foram expostas a uma situação experimental que consistia em resolver um quebra-cabeça. Participante e confederado tinham acesso ao seu próprio quebra-cabeça e ao quebra-cabeça do confederado/participante através de duas telas de computador sincronizadas e eles podiam colocar peças no seu quebra-cabeça ou no quebra-cabeça do outro. Caso o participante ou o confederado colocasse peças em seu próprio quebra-cabeça, eles ganhariam 10 pontos individualmente (alternativa individual). E se eles colocassem peças no quebra-cabeça do seu par, ambos ganhariam 10 pontos (alternativa de cooperação).

Todas as duplas foram expostas a sucessivas condições experimentais na qual a porcentagem da resposta do confederado de colocar peças no quebra-cabeça do participante variava de 0 a $100 \%$. Enquanto o primeiro grupo foi exposto a uma 
porcentagem crescente de "participação do confederado (0 - 25 - 50 - 75 - 100\%), o segundo grupo foi exposto a uma porcentagem decrescente (100 - $75-50-25-0 \%)$. Por exemplo, durante a condição experimental de $0 \%$, o confederado nunca colocava peças no quebra-cabeça do participante, independente da escolha do mesmo, enquanto que na condição experimental de 75\%, o confederado colocou 37 peças (em um total de 50 peças) no quebra-cabeça do participante, ou seja, à medida que a porcentagem aumentava, o número de peças que o confederado colocava no quebra-cabeça do participante também aumentava. Os resultados deste experimento demonstraram que a escolha pela alternativa de cooperação dos participantes teve uma função direta com a escolha do confederado, ou seja, os participantes escolhiam colocar peças no quebra-cabeça do confederado somente quando este também o fizesse.

Alguns estudos, como o de Schmitt e Marwell (1972) e Shimoff e Matthews (1975), sugerem que a iniquidade de reforço pode ser vista como aversiva. Logo, em uma situação entre cooperar/competir ou trabalhar individualmente, os indivíduos acabam optando pela alternativa individual para não serem expostos a essa iniquidade. Paralela a essa discussão, estudos como o do Ribes-Iñesta, et al (2010), sugerem que a escolha de um dos participantes de uma dupla (ou confederado) pode gerar controle discriminativo para a resposta do outro participante. A partir disso, pode-se perguntar se uma história de cooperação bem sucedida entre indivíduo A e B, pode colocar a resposta de A sob controle da resposta de B (ou vice versa) de modo que em uma situação que envolva iniquidade, o resultado seja diferente do esperado na ausência dessa história. Por exemplo, o indivíduo A produziria iniquidade desfavorável para ele após ser exposto a uma história de cooperação bem sucedida em que a iniquidade tenha sido favorável a ele? Essa discussão pode contribuir para debater com mais especificidade a questão sobre o caráter supostamente aversivo da iniquidade. Além disso, pode contribuir para descrever se esse suposto caráter aversivo seria intrínseco à situação de iniquidade ou se poderia ser modificado por contingências de reforço especialmente arranjadas que envolvem o comportamento de um outro indivíduo.

A fim de responder essa pergunta, o presente trabalho teve como objetivo investigar qual é o efeito que diferentes histórias experimentais de cooperação têm sobre a escolha de um participante em uma situação de iniquidade desfavorável. A história experimental foi manipulada por meio da escolha do confederado em um sentido análogo à manipulação feita por Ribes-Iñesta, et al (2010). Nesse caso, uma história de cooperação significa uma 
história em que o confederado atua de modo a aumentar os ganhos do participante. Ausência dessa história significaria que o confederado não atua de maneira a aumentar os ganhos do participante quando poderia fazê-lo. Em outras palavras, o objetivo foi investigar se o participante produziria iniquidade desfavorável para ele e favorável para o confederado após ser exposto a uma história de cooperação bem sucedida com o confederado (história na qual confederado produziu iniquidade favorável ao participante). 


\section{Método}

\section{Participantes}

Após a aprovação da pesquisa por um Comitê de Ética em Pesquisa, 44 estudantes universitários, com mais de 18 anos de idade e de ambos os sexos, foram recrutados no próprio campus onde estudam. Todos os participantes assinaram um Termo de Consentimento Livre e Esclarecido (TCLE - Apêndice A), e seus gastos com deslocamento foram ressarcidos.

\section{Ambiente e Material}

A pesquisa foi realizada em uma sala do Laboratório Didático de Análise Experimental do Comportamento da Universidade de São Paulo. Na sala havia duas mesas, duas cadeiras (uma mesa e uma cadeira para o participante e uma mesa e uma cadeira para o confederado), um biombo e uma lousa branca. As mesas e as cadeiras ficaram dispostas lado a lado com o biombo situado entre elas. A lousa branca foi colocada na parede em frente ao participante e ao confederado. A experimentadora ficava em pé ao lado da lousa branca para ter acesso visual ao participante e ao confederado e para que ambos pudessem vê-la, porém, o contato visual entre o participante e o confederado era impossibilitado pela presença do biombo. A experimentadora registrava na lousa as escolhas e os pontos ganhos por cada um em todas as tentativas do experimento, permitindo que ambos acompanhassem continuamente as escolhas e os pontos do outro. Nas mesas do participante e do confederado havia dois cartões, um azul e um verde, um lápis e uma folha de anotação, na qual era solicitado que ambos anotassem o cartão escolhido por cada um e os pontos recebidos em cada tentativa. 
A Figura 1 exibe a sala de coleta de dados e a Figura 2 a disposição dos cartões na mesa do participante e do confederado.

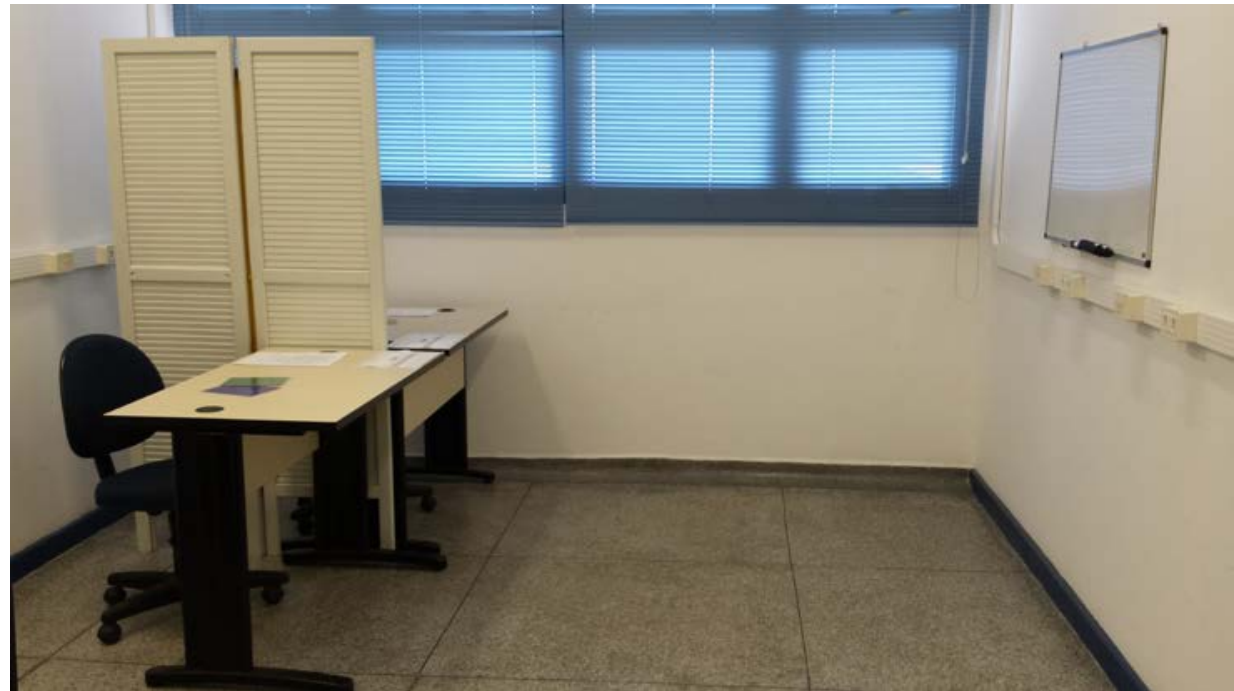

Figura 1. Sala de coleta de dados

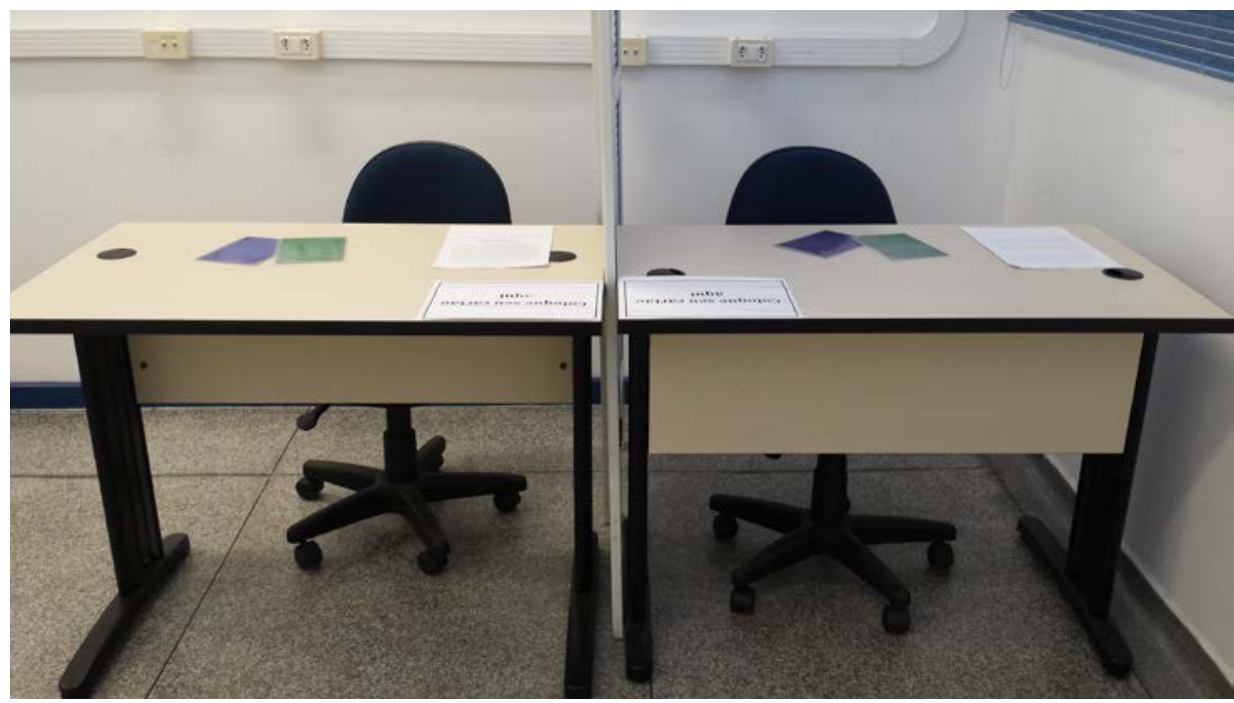

Figura 2. Disposição dos cartões na mesa do participante e do confederado

\section{Procedimento}

Os participantes foram distribuídos em dois grupos (Cooperação e Individual), sendo que cada participante formou uma dupla com um confederado. Os participantes não sabiam que o confederado era um experimentador auxiliar. 
Após ler e assinar o TCLE, o participante entrava na sala experimental com o confederado já sentado em uma das cadeiras, atrás do biombo, de modo a evitar contato entre ambos. Em seguida, uma folha com instruções gerais era entregue ao participante e ao confederado. O experimentador pedia que as instruções fossem lidas silenciosamente. As instruções gerais fornecidas aos participantes foram semelhantes àquelas apresentadas por Abreu-Rodrigues et al (2002) com algumas modificações:

"Este estudo não é sobre inteligência e não visa avaliar suas habilidades intelectuais. Ao seu término, você receberá maiores explicações. Você estará trabalhando com um parceiro e ambos terão uma tarefa idêntica para executar durante o experimento. Você e seu parceiro receberão, cada um, dois cartões (um azul e um verde). Quando a experimentadora disser a palavra 'Atenção', você terá duas opções de escolha: (1) Colocar a mão sobre o cartão azul; e (2) Colocar a mão sobre o cartão verde. Após sua escolha, o experimentador dirá a palavra: Agora. Neste momento, coloque o cartão escolhido no local indicado na sua mesa para que você e seu parceiro vejam a escolha feita por cada um ao longo do experimento. A cada tentativa, você receberá um determinado número de pontos. A quantidade de pontos que você irá receber depende da sua escolha e da escolha do seu parceiro. O experimentador lhe avisará quando esta sessão terminar. Por favor, permaneça sentado e NÃO CONVERSE com o seu parceiro ou com o experimentador durante a sessão. Todas as instruções estão contidas nesta folha. Em caso de dúvida, releia as instruções (não faça perguntas ao experimentador). Quando estiver pronto (a) para começar, levante sua mão direita”.

A tarefa consistia em escolher entre um cartão azul e um cartão verde. Caso o participante e o confederado escolhessem o cartão azul, a alternativa de cooperação entrava em vigor; e, caso um dos dois ou ambos escolhessem o cartão verde, a alternativa individual entrava em vigor. Os participantes de cada grupo foram expostos a três fases experimentais: Fase Inicial, Fase de História de Cooperação e Fase de Teste (Grupo Cooperação); e Fase Inicial, Fase de História Individual e Fase de Teste (Grupo Individual). Os pontos foram distribuídos a depender da fase experimental e da escolha do participante e confederado (ver Tabela 1). 
Tabela 1 - Pontos recebidos pelo participante e pelo confederado de ambos os grupos experimentais, número de tentativas em cada fase experimental e escolha do confederado por grupo

\begin{tabular}{|c|c|c|c|c|c|c|c|}
\hline \multirow{3}{*}{ Fase } & \multirow{2}{*}{\multicolumn{2}{|c|}{$\begin{array}{c}\text { Combinações de } \\
\text { cores }\end{array}$}} & \multicolumn{2}{|c|}{ Pontos } & \multirow{2}{*}{$\begin{array}{c}\text { Número de } \\
\text { tentativas }\end{array}$} & \multicolumn{2}{|c|}{ Escolha do confederado } \\
\hline & & & \multirow[t]{2}{*}{ Participante } & \multirow[t]{2}{*}{ Confederado } & & Grupo & Grupo \\
\hline & Verde & Verde & & & \multirow{4}{*}{4} & \multirow{4}{*}{\multicolumn{2}{|c|}{ Verde-Azul-Verde-Azul }} \\
\hline \multirow{3}{*}{ Inicial } & Verde & Azul & 2 & 2 & & & \\
\hline & Azul & Verde & & & & & \\
\hline & Azul & Azul & 5 & 2 & & & \\
\hline \multirow{4}{*}{ História } & Verde & Verde & & & \multirow{4}{*}{15 ou mais } & \multirow{4}{*}{ Azul } & \multirow{4}{*}{ Verde } \\
\hline & Verde & Azul & 2 & 2 & & & \\
\hline & Azul & Verde & & & & & \\
\hline & Azul & Azul & 5 & 2 & & & \\
\hline \multirow{4}{*}{ Teste } & Verde & Verde & & & \multirow{4}{*}{15} & \multirow{4}{*}{ Azul } & \multirow{4}{*}{ Azul } \\
\hline & Azul & Verde & 2 & 2 & & & \\
\hline & Verde & Azul & & & & & \\
\hline & Azul & Azul & 2 & 5 & & & \\
\hline
\end{tabular}

Fase Inicial. Os pontos foram distribuídos da seguinte forma: quando ambos ou somente um dos dois membros da dupla escolhiam a alternativa individual (cartão verde), os dois ganhavam 2 pontos. Quando ambos escolhiam a alternativa de cooperação (cartão azul), o participante ganhava 5 pontos e o confederado 2 pontos. A fase foi composta por somente quatro tentativas, sendo que o confederado escolheu o cartão verde e azul alternadamente (verde-azul-verde-azul). O objetivo dessa fase foi permitir que os participantes fossem expostos às duas possíveis possibilidades de ganhar pontos no experimento. Por exemplo, se o confederado escolhesse o cartão verde em todas as tentativas do experimento, os participantes do Grupo Individual não teriam a possibilidade de receber 5 pontos em nenhuma das tentativas e não seria exposto à contingência de cooperação.

No início da Fase Inicial, em ambos os grupos, a experimentadora fornecia uma folha para o participante com uma instrução específica sobre a forma de ganhar pontos:

“Caso você escolha o cartão azul, e o participante ao seu lado também escolha o cartão azul (combinações: Azul - Azul), você ganhará 5 pontos e o participante ao seu lado 
ganhará 2 pontos. Caso você e/ou o participante ao seu lado escolha o cartão verde (combinações: Azul - Verde; Verde - Azul ou Verde - Verde), ambos ganharão 2 pontos”.

O confederado recebia simultaneamente com o participante uma folha com instruções específicas, porém, as instruções para o confederado descreviam que o mesmo receberia somente 2 pontos, independente das escolhas. Todos os participantes foram submetidos a esta fase.

Fase de História de Cooperação. Os pontos foram distribuídos exatamente como na Fase Inicial, porém foram realizadas ao menos 15 tentativas nas quais o confederado foi orientado a escolher a alternativa de cooperação (cartão azul), o que permitia ao participante ganhar o máximo de pontos possível. O participante só era exposto à Fase de Teste caso escolhesse a alternativa de cooperação em uma proporção igual ou maior a 10/15, sendo que nas últimas três tentativas o participante deveria escolher o cartão azul. Quando o participante não atingia o critério de encerramento de fase, ele era exposto novamente a mais 15 tentativas, sendo dispensado do experimento caso não atingisse o critério novamente. Foram expostos a esta fase 29 participantes. Desse total, 14 foram excluídos do experimento porque não atingiram o critério de encerramento.

Fase de História Individual. Idêntica à fase descrita anteriormente, com a exceção de que o confederado sempre escolhia a alternativa individual (cartão verde), não permitindo que o participante ganhasse o máximo de pontos. Nessa fase não havia critério de encerramento, logo, o participante foi exposto a somente 15 tentativas no total. Foram expostos a esta fase 15 participantes.

Fase de Teste. Foram realizadas 15 tentativas, e os pontos distribuídos da seguinte forma: quando ambos ou somente um dos dois escolhessem a alternativa individual (cartão verde), os dois ganhavam 2 pontos. Quando ambos escolhessem a alternativa de cooperação (cartão azul), o participante ganhava 2 pontos e o confederado 5 pontos. Nesta fase, os pontos para a alternativa de cooperação foram invertidos, e o confederado sempre escolheu a alternativa com maior magnitude de reforço para si, ou seja, o cartão azul. No início da fase, a experimentadora forneceu outra folha com a seguinte instrução específica para o participante:

“Caso você escolha o cartão azul, e o participante ao seu lado também escolha o cartão azul (combinações: Azul - Azul), você ganhará 2 pontos e o participante ao seu lado ganhará 5 pontos. Caso você e/ou o participante ao seu lado escolha o cartão verde (combinações: Azul - Verde; Verde - Azul ou Verde - Verde), ambos ganharão 2 pontos”. 
O confederado também recebia uma folha com instruções específicas, porém, com a matriz de ganho invertida (vide Tabela 1). Todos os participantes do experimento, exceto àqueles que foram excluídos na Fase de História de Cooperação, foram expostos a esta fase. 


\section{Resultados}

No total, 44 participantes foram recrutados para participar do experimento, sendo que 15 participantes integraram o Grupo Individual e 29 participantes o Grupo Cooperação. No Grupo Cooperação, 14 participantes não atingiram o critério estabelecido na Fase de História de Cooperação, sendo eliminados do experimento sem que seus dados fossem analisados.

A Figura 3 exibe o número total de escolhas do cartão azul e verde em todas as fases do experimento dos dois grupos.

Observa-se que todos os participantes do Grupo Cooperação escolheram o cartão azul em pelo o menos duas tentativas da Fase Inicial e em dez tentativas na Fase de História (critério exigido para ser exposto à Fase de Teste). Na Fase de Teste, 12 participantes escolheram o cartão azul, no mínimo, em dez tentativas, e três participantes (P1, P2 e P3) não escolheram o cartão azul em nenhuma das tentativas. Nota-se também na Figura 3 que os participantes do Grupo Individual, durante a Fase Inicial, escolheram o cartão azul pelo menos em uma tentativa de quatro. Na Fase de História, os participantes variaram suas escolhas entre os dois cartões, porém escolheram o cartão azul em quantidade maior que o cartão verde, com exceção de um participante (P22), que escolheu mais o cartão verde (13 de 15 tentativas). Na Fase de Teste, todos os participantes desse grupo escolheram o cartão verde em pelo menos dez de 15 tentativas. 
Grupo Cooperação

Grupo Individual

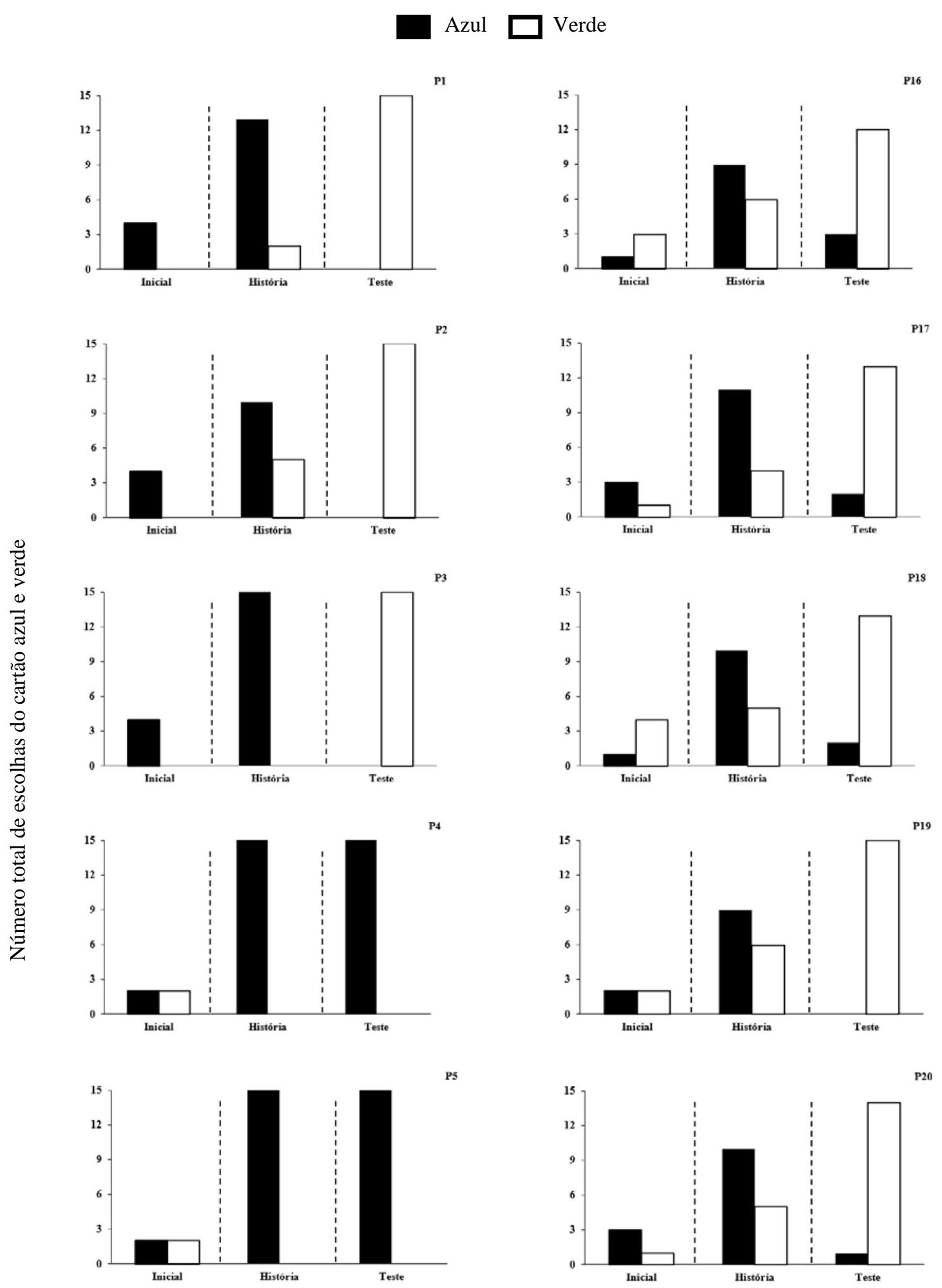

Fase Experimental 

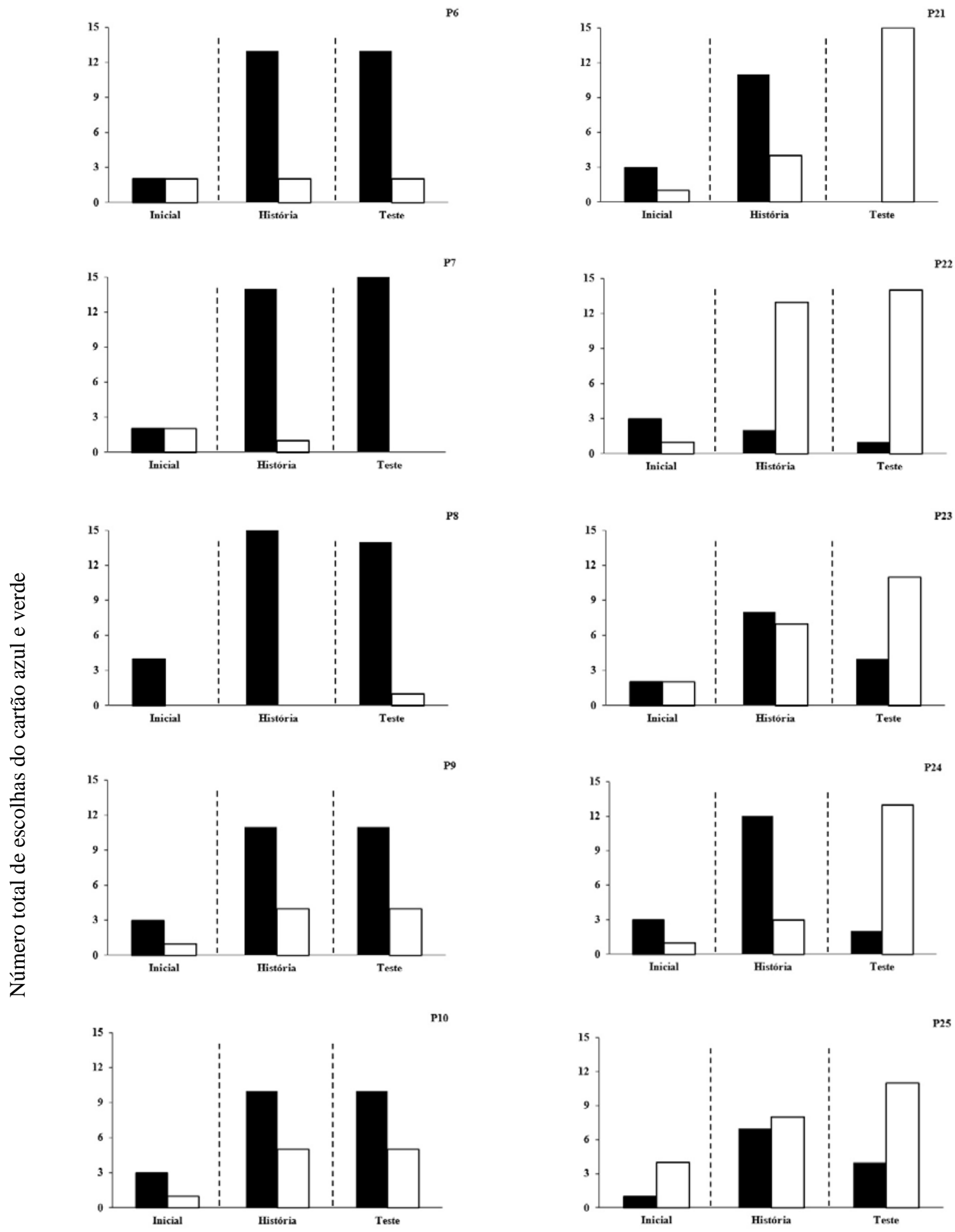

Fase Experimental 

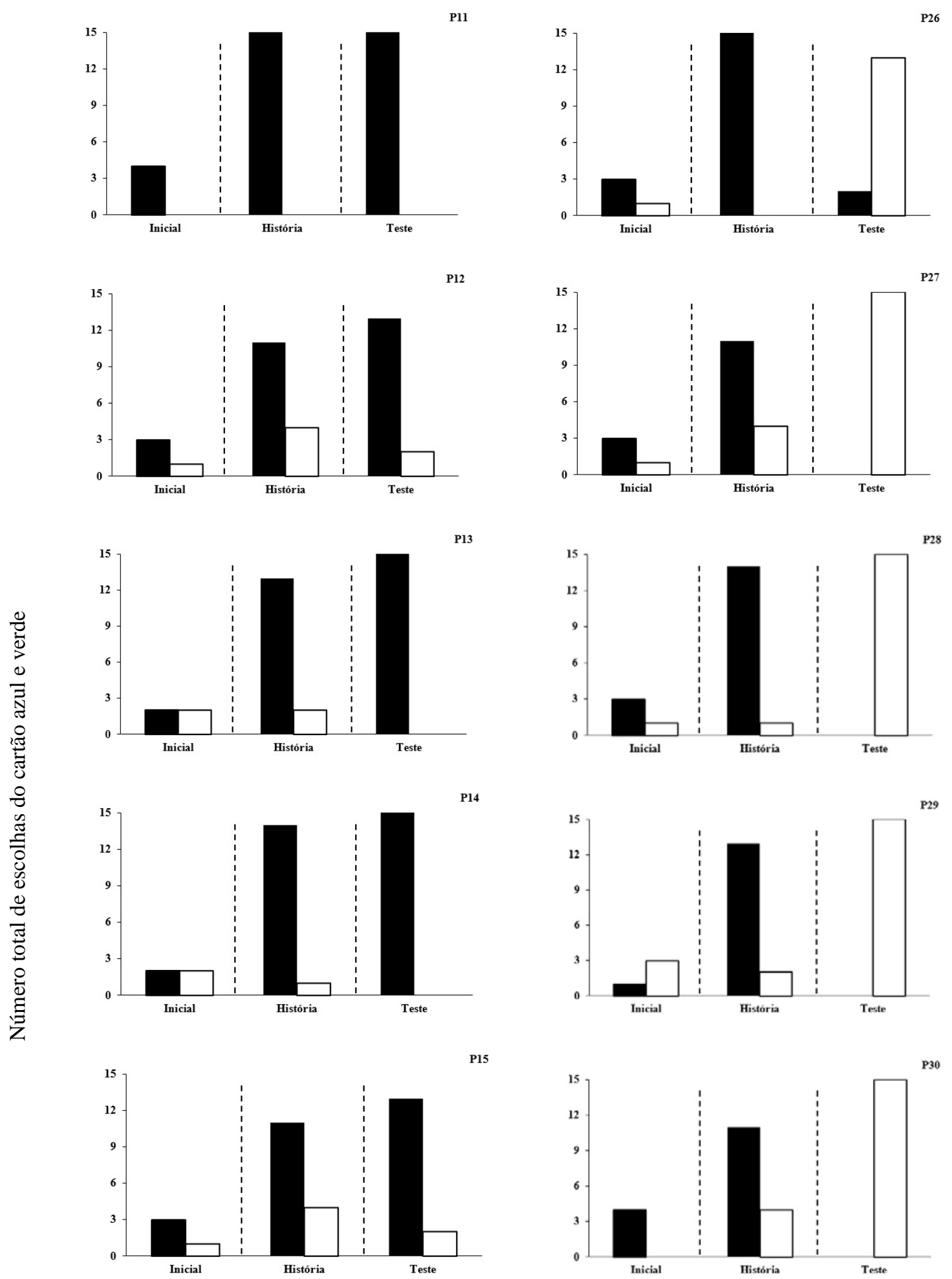

Fase Experimental

Figura 3. Número total de escolhas do cartão azul e do cartão verde de cada participante do Grupo Cooperação e do Grupo Individual nas Fases Inicial, de História e de Teste. 
A Figura 4 apresenta a média de escolhas do cartão azul do Grupo Cooperação e do Grupo Individual na Fase de História e na Fase Teste.

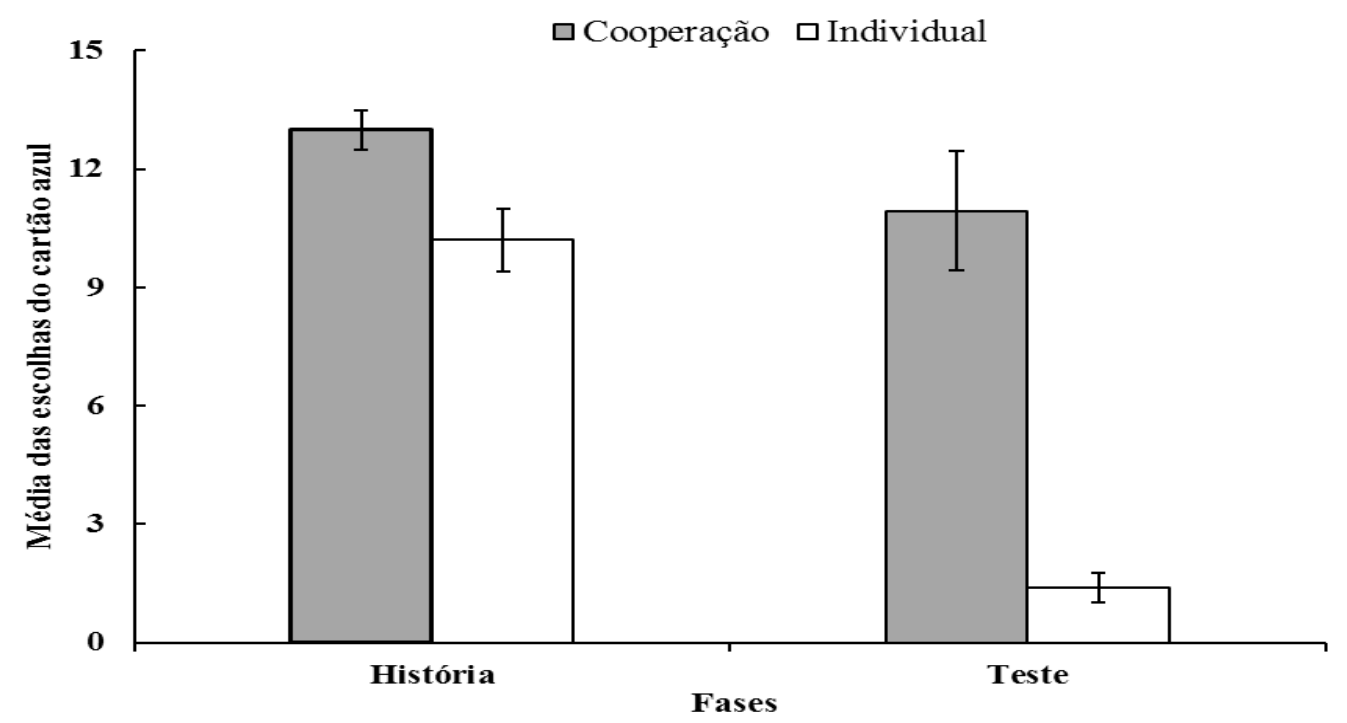

Figura 4. Média de escolhas do cartão azul pelos participantes do Grupo Cooperação e do Grupo Individual na Fase de História e na Fase de Teste. A barra cheia de cor cinza representa a média total de escolhas do cartão azul de todos os participantes do Grupo Cooperação e a barra vazia representa a média total de escolhas do cartão azul de todos os participantes do Grupo Individual. O erro padrão corresponde à linha vertical acima das barras.

Nota-se a partir da Figura 4 que a média de escolhas do cartão azul foi maior para o Grupo Cooperação do que para o Grupo Individual tanto na Fase de História quanto na Fase de Teste. Todos os participantes do Grupo Individual escolheram o cartão verde na maioria das tentativas durante a Fase Teste, e os participantes do Grupo Cooperação, com exceção de P1, P2 e P3, escolheram quase exclusivamente o cartão azul na Fase de Teste (vide Figura 3). A média de escolhas do cartão azul na Fase de História do Grupo Cooperação foi de 13 escolhas e do Grupo Individual é de aproximadamente dez escolhas. Na Fase de Teste, a média de escolhas do cartão azul do Grupo Cooperação foi de aproximadamente 11 escolhas e do Grupo Individual de aproximadamente uma escolha.

O erro padrão da média indica uma estimativa do desvio padrão da distribuição das médias na amostra do estudo. Na figura, observa-se que a barra do erro padrão é maior no Grupo Individual na Fase de História e no Grupo Cooperação na Fase de Teste. Assim como descrito anteriormente, os participantes do Grupo Individual variaram entre os dois cartões na Fase de História. A barra de erro padrão foi maior para o Grupo Cooperação na Fase de Teste possivelmente pelo fato de três participantes (P1, P2 e P3) não terem 
escolhido o cartão azul em nenhuma das tentativas, diferente dos outros participantes desse grupo. O erro padrão do Grupo Cooperação foi de 0,5 na Fase de História e 1,51 na Fase de Teste. Do Grupo Individual foi de 0,81 na Fase de História e de 0,38 na Fase de Teste. O Teste T-student, que comparou a média de escolhas do cartão azul dos dois grupos na Fase de História e na Fase de Teste, aponta que existe diferença estatisticamente significativa entre as médias dos dois grupos ao nível de significância de $5 \%(p \leq 0,05)$ para um intervalo de confiança de 95\%.

As Figuras 5 e 6 exibem o número total de escolhas do cartão azul de cada grupo em blocos de três tentativas na Fase de História e na Fase de Teste.

O número total de escolhas do cartão azul dos participantes do Grupo Cooperação foi maior que do Grupo Individual tanto na Fase de História quanto na Fase de Teste em todos os blocos de três tentativas, com exceção do primeiro bloco, na qual os participantes de ambos os grupos somam um total de 33 escolhas do cartão azul. No decorrer da sessão experimental, o número total de escolhas do cartão azul dos participantes do Grupo Cooperação aumenta a cada bloco, enquanto o do Grupo Individual tende a diminuir. O total de escolhas do cartão azul do Grupo Individual foi 33, 34, 27, 31 e 28 nos blocos 1, 2, 3, 4 e 5, respectivamente, e do Grupo Cooperação foi 33, 39, 40, 41 e 45 nos blocos 1, 2, 3, 4 e 5 , respectivamente.

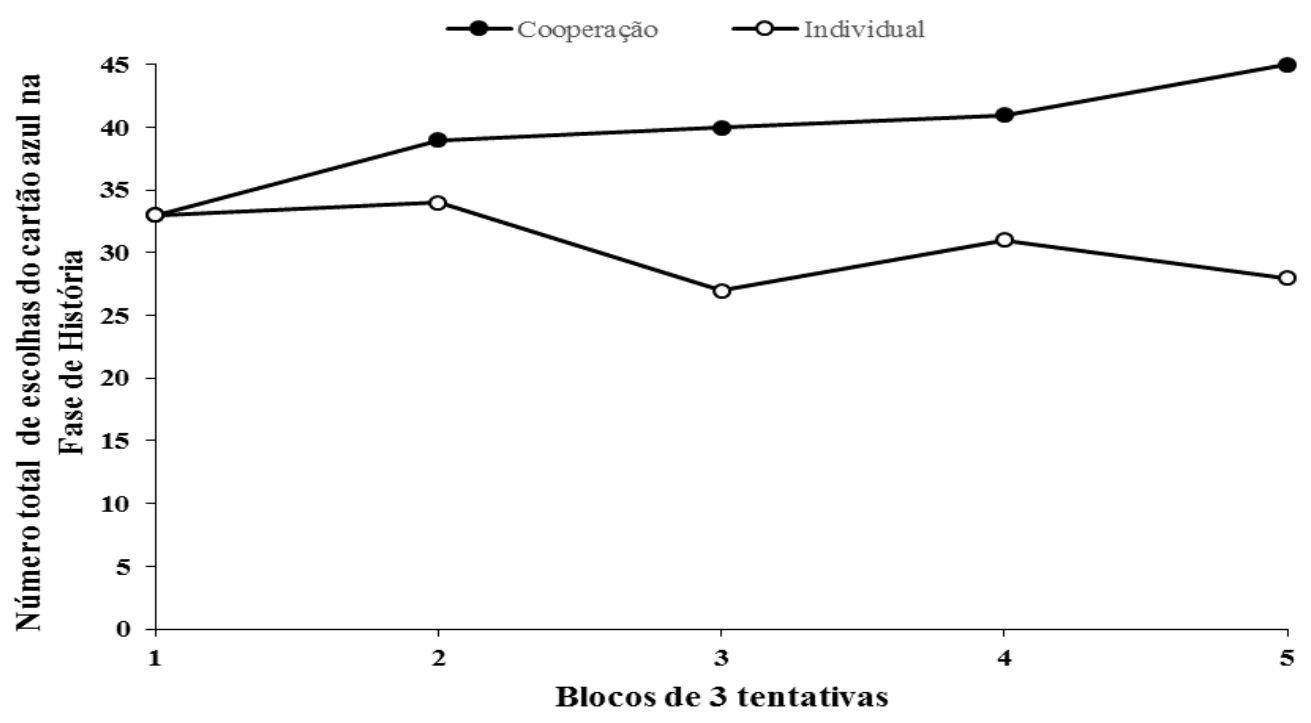

Figura 5. Número total de escolhas do cartão azul de cada grupo em blocos de três tentativas na Fase de História. Os participantes do Grupo Cooperação estão representados com círculos cheios e os participantes do Grupo Individual estão representados com círculos vazios. Cada bloco de três tentativas representa a soma das escolhas do cartão azul dos onze participantes de cada grupo naquele bloco. 


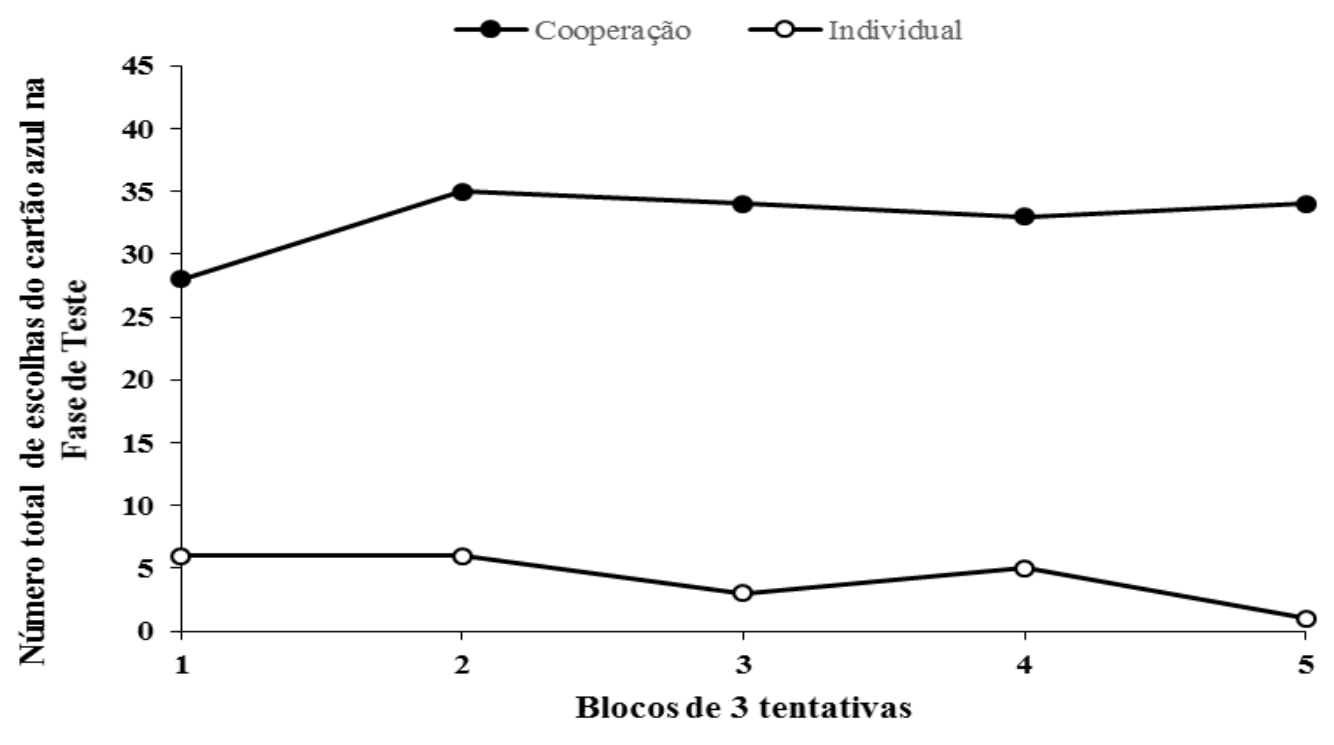

Figura 6. Número total de escolhas do cartão azul de todos os participantes de cada grupo em blocos de três tentativas na Fase de Teste. Os participantes do Grupo Cooperação estão representados com círculos cheios e os participantes do Grupo Individual estão representados com círculos vazios. Cada bloco de três tentativas representa a soma das escolhas do cartão azul dos onze participantes de cada grupo naquele bloco.

Na Fase de Teste, observa-se também que o número total de escolhas do cartão azul em cada bloco é maior para os participantes do Grupo Cooperação do que para os participantes do Grupo Individual. No primeiro bloco de três tentativas, o número total de escolha do cartão azul na Fase de Teste é seis para o Grupo Individual e 28 para o Grupo Cooperação. No decorrer das tentativas, os participantes do Grupo Individual diminuíram ainda mais a quantidade de escolhas do cartão azul (somente uma escolha do P23 no último bloco de três tentativas), enquanto os participantes do Grupo Cooperação aumentaram a quantidade de escolhas do cartão azul (34 escolhas no último bloco).

A Figura 7 exibe a probabilidade relativa de escolhas do cartão azul de cada participante na Fase de Teste e o ganho relativo na Fase de História dos dois grupos do experimento. 


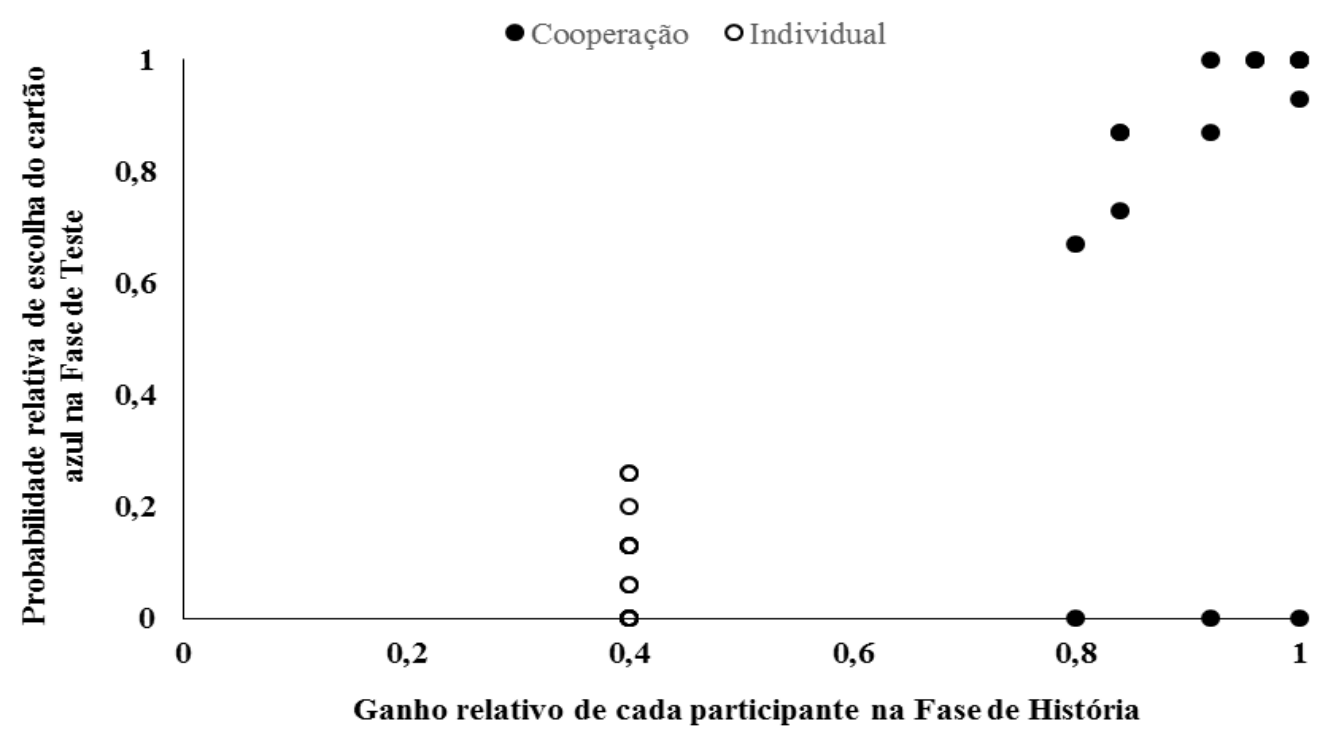

Figura 7. Probabilidade relativa de escolha do cartão azul na Fase de Teste e o ganho relativo na Fase de História de cada participante do Grupo Cooperação e do Grupo Individual. O círculo cheio representa os participantes do Grupo Cooperação e o círculo vazio representa os participantes do Grupo Individual.

A partir dos dados representados na Figura 7, pode-se afirmar que, quanto maior é o ganho relativo na Fase de História, maior é a probabilidade relativa de escolha do cartão azul na Fase Teste. As probabilidades de escolha do cartão azul do Grupo Individual estão sobrepostas para alguns participantes: seis participantes (P19, P21, P27, P28, P29 e P30) em 0,0 (zero), dois participantes (P20 e P22) em 0,7, quatro participantes (P17, P18, P23 e P26) em 0,13 e dois participantes (P24 e P25) em 0,26. O mesmo ocorre com os participantes do Grupo Cooperação: três participantes (P4, P5 e P11) em 1,0, dois participantes (P7 e P14) no ponto de 0,93 (probabilidade) e 1,0 (ganho) e dois participantes (P12 e P15) no ponto de 0,84 (probabilidade) e 0,87 (ganho). A partir dessas informações, nota-se que o fato de todos os participantes do Grupo Individual terem recebido somente 2 pontos em todas as tentativas da Fase de História diminuiu consideravelmente a probabilidade de escolha do cartão azul na Fase de Teste, ao comparar esses participantes com os do Grupo Cooperação. A maior probabilidade de escolha do cartão azul na Fase de Teste para o Grupo Individual foi de 0,27.

Ao observar os círculos cheios que representam os participantes do Grupo Cooperação, percebe-se que quanto maior o ganho relativo dos participantes na Fase de História, maior é probabilidade de escolher o cartão azul na Fase de Teste. Exceção disso é a escolha de três participantes (P1, P2 e P3) que, mesmo ganhando quase ou o total de 
pontos na Fase de História (0,92, 0,8 e 1,0), não escolheram o cartão azul em nenhuma das alternativas na Fase de Teste. 


\section{Discussão}

O presente estudo teve como objetivo investigar o efeito de uma história de cooperação sobre as escolhas posteriores de um participante entre duas alternativas que disponibilizam reforços em uma situação de iniquidade desfavorável. A história experimental foi manipulada por meio das escolhas feitas por um confederado em uma fase prévia à fase com iniquidade desfavorável ao participante. No Grupo Cooperação, o confederado escolhia sempre o cartão azul viabilizando a iniquidade favorável ao participante. Ou seja, ao escolher o cartão azul (alternativa de cooperação), o confederado permitia que o participante recebesse todos os pontos possíveis (5 pontos) enquanto ele receberia somente 2 pontos. Diferentemente, no Grupo Individual, o confederado escolhia somente o cartão verde (alternativa individual), não permitindo a iniquidade favorável ao participante. Após essa breve história controlada experimentalmente, os participantes foram expostos a uma Fase de Teste na qual a iniquidade de reforços era desvantajosa ao participante. O objetivo dessa fase foi investigar se as diferentes histórias com o confederado iriam influenciar na escolha do participante na direção de produzir iniquidade desfavorável.

Os resultados mostraram que os participantes do Grupo Cooperação escolheram a alternativa de cooperação na Fase de Teste em uma média de 13 em 15 das tentativas, ou seja, em 13 de 15 tentativas esses participantes produziram iniquidade desfavorável a eles. A partir desses dados, é possível afirmar que, nas presentes condições, uma história de cooperação bem sucedida entre indivíduo A e B pode aumentar a chance de produção de ganhos desiguais mesmo que a desigualdade seja desfavorável. Esses resultados contradizem a sugestão principal do estudo de Schmitt e Marwell (1972) e Shimoff e Matthews (1975). Em ambos os estudos, os resultados sugerem que a iniquidade de reforços possui propriedades aversivas, de modo que os participante prefiram a condição individual a condição de cooperação ou competição quando estas envolvem iniquidade. Com base nos resultados dos participantes do Grupo Cooperação é possível afirmar que o fato da iniquidade de reforços apresentar ou não propriedades aversivas pode depender mais de outras variáveis do que necessariamente da iniquidade em si.

Diferente dos participantes do Grupo Cooperação, os participantes do Grupo Individual escolheram a alternativa de cooperação em média 2 de 15 tentativas. Nesse 
grupo, o confederado não permitiu que o participante recebesse todos os pontos possíveis na Fase de História. Com isso, na Fase de Teste, o participante também não permitiu que a iniquidade de reforços entre participante e confederado se estabelecesse, escolhendo a alternativa individual em 11 de 15 tentativas. Ao escolher a alternativa individual na Fase de Teste, o participante estabelecia uma condição de equidade de pontos entre ele e o confederado, pois ao realizar essa escolha, ambos recebiam a mesma quantidade de pontos.

A partir dos resultados descritos acima, é possível afirmar que a escolha do confederado na Fase de História influenciou diretamente a escolha dos participantes dos dois grupos nas condições de teste. Esses dados corroboram aqueles resultados encontrados nos estudos Schmitt e Marwell (1972, Experimento 2) e por Shimoff e Mathews (1975). Ambos os estudos demonstraram que a escolha do participante com iniquidade favorável (ou confederado no caso do estudo do Shimoff e Matthews, 1975) de não dividir pontos extras com os participantes com iniquidade desfavorável, diminuia as chances destes participantes escolherem a alternativa de cooperação. No Experimento 2 do estudo do Schmitt e Marwell (1972), os participantes foram expostos a uma condição na qual o participante que estivesse exposto à iniquidade favorável tinha a possibilidade de dividir os pontos extras com o participante exposto a iniquidade desfavorável. Notou-se que os participantes em desvantagem passaram a escolher a alternativa individual caso o participante em vantagem não transferisse pontos para ele. O mesmo foi possível observar no estudo de Shimoff e Matthews (1975) quando os participantes deixaram de escolher a alternativa de cooperação ou mudaram a condição de iniquidade para a condição de equidade após serem expostos a manipulação em que o confederado tinha a possibilidade de dividir os pontos extras com os participantes, mas não o fez. Esses dois estudos apresentaram variabilidade nos resultados que dificultam uma clara conclusão sobre o papel da iniquidade sobre o comportamento de escolha entre alternativas de cooperar ou trabalhar individualmente. Uma parte dessa variabilidade pode ser explicada pela variável controlada no presente estudo: a história do participante com o confederado (ou outro participante) e os ganhos decorrentes dessa história. Essa história pode estabelecer um controle de estímulos tal sob o comportamento do participante de forma tal que a iniquidade passe a ser produzida e não evitada.

Com os resultados do presente estudo, nota-se que a variabilidade dos resultados nos estudos de Schmitt e Marwell (1972) e Shimoff e Mathews (1975) pode ser parcialmente explicada pela extensa e não controlada história experimental na qual os 
participantes desses dois estudos foram expostos. Nota-se que ao se controlar a história experimental, é possível diminuir ou até mesmo anular a variabilidade dos resultados. No presente estudo, em um total de 15 participantes do Grupo Cooperação, somente três participantes apresentaram um padrão de escolhas diferente dos demais participantes e não cooperaram na Fase de Teste. No Grupo Individual, por outro lado, todos os 15 participantes apresentaram o mesmo padrão de escolha e não cooperaram com o confederado na Fase de Teste.

Os dados do presente estudo replicam dados produzidos por Ribes-Iñesta, et al (2010). Os autores demonstraram que a escolha pela alternativa de cooperação dos participantes teve relação direta com a escolha do confederado em cooperar. Nesse sentido, os dados do presente estudo estendem as conclusões de Ribes-Iñesta et al (2010) a respeito da história bem sucedida de cooperação para o que pode ser encontrado em uma situação de teste com iniquidade desfavorável. Com essa extensão, a questão da história de cooperação bem sucedida pode ser vista como ainda mais poderosa na alteração de funções comportamentais presentes em relações sociais.

Comparando-se o presente estudo com os de Schmitt e Marwell (1972) e Shimoff e Matthews (1975), algumas diferenças de procedimentos devem ser também mencionadas. Uma dessas diferenças é a natureza de reforçadores utilizadas nos três estudos. Schmitt e Marwell (1972) e Shimoff e Matthews (1975) trocavam os pontos recebidos pelos participantes por dinheiro no final das sessões experimentais e o presente estudo utilizou somente pontos como reforçadores. Um estudo que evidencia que essa diferença no procedimento pode ser importante para a análise da generalidade dos presentes resultados é o estudo de Benvenuti e de Toleto (submetido). O objetivo foi investigar quais variáveis sociais influenciam o comportamento supersticioso e estimativas de controle em situação de apresentação de pontos não contingentes ao comportamento. Vinte participantes foram expostos a um esquema múltiplo com dois componentes: tempo variável (VT) e extinção. No componente VT, os pontos foram liberados em média a cada $8 \mathrm{~s}$, independente do comportamento dos participantes. No componente extinção, nenhum ponto era liberado. Os participantes foram distribuídos em dois grupos. Em um grupo, antes do experimento os participantes recebiam uma informação de que a cada 20 pontos recebidos, o participante recebia um vale que poderia ser trocado por uma fotocópia após a sessão experimental. No outro grupo, os participantes recebiam somente pontos. Os resultados do estudo indicaram que os participantes do grupo que os pontos eram trocados pelo vale 
fotocópias apresentaram maiores taxas de respostas do que os participantes do grupo que só receberam pontos como reforçador, bem como estimaram maior de controle sobre a situação. A informação de que pontos ganhos podem ser trocados por algo com valor para os participantes pode, portanto, produzir algum efeito extra sobre a motivação dos participantes na tarefa. Essa mudança na motivação (entendida genericamente como um aumento na taxa geral de respostas na tarefa) pode interagir com a questão da iniquidade em contexto social experimentalmente arranjado. Nesse sentido, explorar essa questão pode ser interessante para delineamentos futuros e pode oferecer informações interessantes sobre a generalidade dos presentes resultados e sobre a questão da aversividade da iniquidade de modo mais geral.

Outra diferença de procedimento que deve ser discutida é a presença do experimentador durante a coleta de dados. Nos estudos de Schmitt e Marwell (1972) e Shimoff e Matthews (1975) os participantes não tinham contato visual com o outro participante (Schmitt \& Marwell, 1972) ou confederado (Shimoff \& Matthews, 1975) e muito menos com o experimentador durante a coleta. No caso do presente estudo, o participante não tinha contato visual com o confederado, porém, a experimentadora permaneceu em frente ao participante e confederado durante todo o tempo de coleta. A experimentadora sinalizava verbalmente e anotava na lousa branca a escolha e os pontos do confederado e do participante em cada tentativa. Uma possível hipótese para a discrepância de resultados nos estudos de Schmitt e Marwell (1975) e do Shimoff e Matthews (1975) e do presente trabalho é que a presença da experimentadora pode ter exercido um controle social extra sobre as escolhas do participantes. Um estudo que indica que esse controle pode ser possível é o de Costa (2009). Nesse estudo, as autoras investigaram o efeito da presença do experimentador sobre a sensibilidade comportamental frente às alterações nas contingências em situações em que o comportamento era instruído. Os resultados indicaram que o controle por instruções é mais forte quando há controle social exercido pela presença do experimentador (para maiores detalhes, ver Costa, 2009). No caso da produção da iniquidade pela escolha do participante por cooperação, a presença do experimentador pode ter um efeito decisivo e poderia ser mais bem explorada em investigações futuras.

Outra possível discussão do procedimento envolve a Fase Inicial, na qual o confederado escolheu o cartão verde e azul alternadamente por 4 vezes. Ao analisar as escolhas individuais dos participantes na Fase Teste, há algumas evidências de que a Fase 
Inicial do experimento pode ter influenciado na escolha dos participantes de algumas tentativas na Fase de Teste. Nove participantes (P16, P17, P18, P20, P22, P23, P24, P25 e P26) de onze do Grupo Individual relataram que o fato do confederado ter escolhido o cartão azul duas vezes na Fase Inicial fez com que ele também escolhesse o cartão azul na Fase Teste pelo o menos uma vez. Seis participantes (P6, P8, P9, P10, P12 e P15) do Grupo Cooperação relataram que escolheram o cartão verde em algumas tentativas da Fase Teste devido ao fato do confederado ter escolhido esse cartão duas vezes na Fase Inicial. Desse modo, é necessário discutir para futuros estudos a necessidade de expor os participantes a essa Fase Inicial. Esses resultados, tanto quanto a relação entre ganhos na Fase de História e escolha do cartão azul na Fase de Teste, sugerem que os participantes de alguma forma “copiam” a resposta do confederado no sentido de retribuirem aquilo que receberam do confederado. Explorar essa questão seria interessante, com um procedomento simplificado como o utilizado no presente estudo, para saber que tipo de controle o confederado exerce sobre a resposta do participante. A história bem sucedida com o confederado faz com que a iniquidade deixe de ser aversiva genericamente ou só até que o participante de algum modo "retribui" o que ganhou pela cooperação do confederado?

Outra importante discussão seria sobre a quantidade de participantes que não atingiram o critério de passagem de fase estabelecido no início do experimento para os participantes que passaram pela fase de História de Cooperação. O Grupo Individual não tinha nenhum critério estabelecido, e por isso, após as 15 tentativas da Fase de História, automaticamente eles eram expostos à Fase de Teste. Os participantes do Grupo Cooperação deveriam escolher a alternativa de cooperação em pelo o menos dez de 15 tentativas, sendo que nas quatro últimas tentativas os participantes deveriam escolher essa alternativa. Dos 29 participantes desse grupo, 14 não atingiram o critério de passagem de fase e seus dados não foram analisados. Ao observar as escolhas desses participantes, percebe-se que talvez o critério estabelecido fosse muito exigente. Para futuras pesquisas, ambos os grupos deveriam ter um critério de passagem de fase que fosse baseado na quantidade mínima de escolhas para a Fase de História, porém, sem necessariamente que as quatro últimas tentativas precisassem ser da alternativa de cooperação. O grande número de participantes descartados exige uma avaliação mais cuidadosa do valor dos eventos ambientais presentes em uma situação de cooperação no laboratório. Possivelmente, o uso assistemático do cartão azul quando havia ganhos consideravelmente mais altos para isso 
indica que a diferença de pontos obtidos por cooperar ou não pode não ser relevante para uma grande parcela dos participantes. O critério de exclusão estabelecido para os particioantes submetidos à Fase de História de Cooperação pode ter ajudado a eliminar os participantes para os quais a principal diferença em termos de ganhos não era relevante. Contudo, o mesmo não ocorreu para os participantes que passarem pela Fase de História Individual.

Ao analisar os dados do presente estudo, notou-se também a necessidade de se coletar um grupo controle. O objetivo de coletar um grupo controle seria observar qual a escolha dos participantes sem que eles fossem expostos a uma história experimental anterior. Para isso, no grupo controle, os participantes seriam expostos diretamente a Fase Teste do experimento, fase na qual o confederado ganha mais pontos do que o participante quando o cartão azul é escolhida por ambos. A partir dos resultados desse grupo, seria possível afirmar com mais clareza que a escolha dos participantes foi controlada pela diferentes histórias de cooperação e individual a que eles foram expostos durante a Fase de História.

Em resumo, os resultados do presente estudo indicaram que um indivíduo produz iniquidade desfavorável a ele e favorável a outro indivíduo em uma situação de iniquidade após serem expostos a uma história de cooperação bem sucedida. Essa afirmação, entretanto, pode se tornar mais robusta com a realização de outros estudos incluindo as mudanças no procedimento sugeridas anteriormente. 


\section{REFERÊNCIAS}

Abreu-Rodrigues, J., Natalino, P. C., \& Aló, R. M. (2002). Instruções e iniquidade de reforços: efeitos sobre o comportamento competitivo. Psicologia: Teoria e Pesquisa, 18, 83-94.

Azrin, N. H. \& Lindsley, O. R. (1956). The reinforcement of cooperation between children. Journal of Abnormal and Social Psychology, 52, 100-102.

Benvenuti, M. F. L \& Toleto, T. N. (submetido). Learning and illusions: instructions affecting motivation and probability to respond in noncontingent task. Learning \& Behavior.

Buskit, W., \& Morgan, D. (1987). Competitive fixed interval performance in humans. Journal of the Experimental Analysis of Behavior, 47, 145-158.

Costa, A. K. (2009) . Efeito da presença do experimentador sobre o seguimento de instruções. Dissertação de Mestrado, Instituto de Psicologia - Universidade de Brasília, Brasil.

De-Farias, A. K. C. R. (2001). Regras e iniquidade entre reforços: influência sobre a escolha entre cooperação e competição. Dissertação de Mestrado, Instituto de Psicologia - Universidade de Brasília, Brasil.

Dougherty, D. M. \& Cherek, D. R. (1994). Effects of social context, reinforcer probability, and reinforce magnitude on human`s choices to compete or not to compete. Journal of the Experimental Analysis of Behavior, 62, 133-148.

Keller, F. S., \& Schoenfeld, W. N. (1950). Principles of psychology. New York: Appleton-Century-Crofts.

Matthews, B. A. (1977). Magnitudes of score differences produced within sessions in a cooperative exchange procedure. Journal of the Experimental Analysis of Behavior, 27, 331-340.

Matthews, B. A. (1979). Effects of fixed and alternated payoff inequity on dyadic competition. Journal of the Experimental Analysis of Behavior, 29, 329-339. 
Mithaug, D. E. (1969). The development of cooperation in alternative task situations. Journal of Experimental Child Psychology, 8, 443-460.

Ribes-Iñesta, E., Rangel, N., Pulido, L., Valdez, U., Ramírez, E., Jiménez, C., \& Hernández, M. (2010). Reciprocity of responding as a determinant of a partial-altruistic behavior in humans. European Journal of Behavior Analysis, 11, 105-114.

Schmitt, D. R. (1998). Social Behavior. In K. Lattal \& M. Perone (Eds.), Handbook of research method in human operant behavior. (pp. 471-505). New York: Plenum Press.

Schmitt, D. R., \& Marwell, G. (1971a). Taking and the disruption of cooperation. Journal of the Experimental Analysis of Behavior, 15, 405-412.

Schmitt, D. R., \& Marwell, G. (1971b). Avoidance of risk as a determinant of cooperation. Journal of the Experimental Analysis of Behavior, 16, 367-374.

Schmitt, D. R., \& Marwell, G. (1972). Withdrawal and reward reallocation as responses to inequity. Journal of Experimental Social Psychology, 8, 207-221.

Shimoff, E., \& Matthews, B. A. (1975). Unequal reinforcer magnitudes and relative preference for cooperation in the dyad. Journal of the Experimental Analysis of Behavior, 24, 1-16.

Skinner, B. F. (1953). Science and human behavior. New York: Free Press.

Skinner, B. F. (1969). Contingencies of reinforcement. A theoretical analysis. New York: Appleton-Century-Crofts.

Todorov, J. C. (2012). Sobre uma definição de comportamento. Revista Perspectivas, 3, 1, 32-37. 


\section{APÊNDICE A. Termo de Consentimento Livre e Esclarecido}

Você está sendo convidado a participar de uma pesquisa sobre interações em pequenos grupos que será realizada no Instituto de Psicologia da Universidade de São Paulo (USP). A sua participação é muito importante, pois estudos desse tipo visam aumentar nosso conhecimento sobre o comportamento humano e poderão, no futuro, contribuir para a discussão de fenômenos sociais.

A atividade que você irá realizar consiste em escolher entre levantar o cartão azul ou o cartão verde. Esta atividade terá duração de, aproximadamente, 40 minutos. Você ficará em uma sala com mobiliário próprio para a tarefa, sendo garantido o seu conforto e segurança. As sessões serão filmadas, porém o uso da filmagem se fará resguardando a ética em relação à identidade dos participantes. A participação nessa pesquisa não implicará em riscos diferentes daqueles a que qualquer pessoa está exposta ao realizar atividades semelhantes em seu dia-a-dia. Os benefícios para você, enquanto participante da pesquisa, serão indiretos, uma vez que essa ampliará os conhecimentos sobre fenômenos sociais e poderá subsidiar futuras intervenções.

Você receberá R\$10,00 por estar participando desta sessão experimental. Este valor serve para ressarcir inteiramente seus gatos com transporte. A sua participação é voluntária e poderá ser encerrada a qualquer momento por solicitação sua, sem necessidade de justificativa e sem qualquer prejuízo. Mesmo que você desista de participar da pesquisa, em qualquer momento, você receberá o valor de $\mathrm{R} \$ 10,00$. Os dados serão utilizados somente para fins científicos, desta ou de outras pesquisas, e serão tratados com o mais absoluto sigilo e confidencialidade, de modo a preservar a sua identidade. A presente pesquisa e o pesquisador responsável que a coordena atendem e atenderão a todas as exigências contidas nas Resolução nº 466 (de 12/12/12) do Conselho Nacional de Saúde que trata das diretrizes e normas regulamentadoras de pesquisas envolvendo seres humanos.

Em caso de dúvidas sobre aspectos éticos, você pode entrar em contato com o Comitê de Ética em Pesquisa com Seres Humanos do Instituto de Psicologia da USP (Av. Prof. Mello de Moraes, 1721, BL G, sala 27, CEP 05508-030, Cidade Universitária, São Paulo-SP; (11) 3091-4182; ceph.ip@usp.br).

Caso concorde em participar, você deverá assinar duas cópias desse termo, sendo que uma das vias ficará com você e a outra ficará em posse do (a) pesquisador (a) responsável. 
Pesquisador Responsável: Carla Jordão Suarez

Contatos do pesquisador: Rua Capistrano de Abreu, 405. Bl B Apto 82. Barra Funda. São Paulo-SP; (11) 2925-5376 ou (11) 95577-1799 e carlinha.suarez@gmail.com

Orientador: Prof. Dr. Marcelo Frota Lobato Benvenuti.

\section{CONSENTIMENTO LIVRE E ESCLARECIDO}

$\mathrm{Eu}$, — após ter recebido todas as informações necessárias e os esclarecimentos devidos, declaro consentir livremente em participar como voluntário desta pesquisa.

São Paulo, de de 